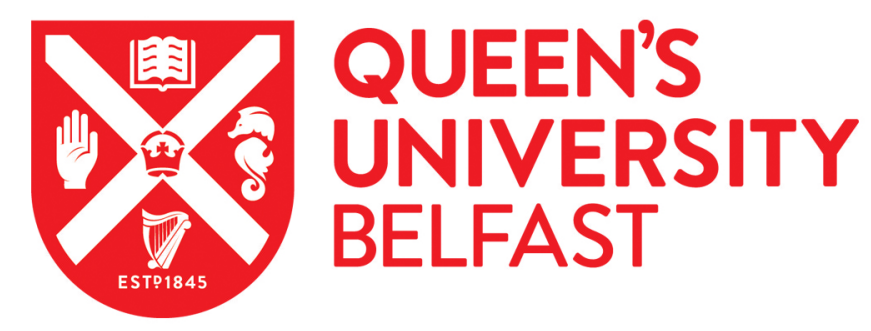

\title{
Osteoblastic differentiation of periodontal ligament stem cells on nonstoichiometric calcium phosphate and titanium surfaces.
}

\author{
Winning, L., Robinson, L., Boyd, A. R., El Karim, I. A., Lundy, F. T., \& Meenan, B. J. (2017). Osteoblastic \\ differentiation of periodontal ligament stem cells on nonstoichiometric calcium phosphate and titanium surfaces.
} Journal of Biomedical Materials Research Part A, 105(6), 1692-1702. https://doi.org/10.1002/jbm.a.36044

Published in:

Journal of Biomedical Materials Research Part A

Document Version:

Peer reviewed version

Queen's University Belfast - Research Portal:

Link to publication record in Queen's University Belfast Research Portal

Publisher rights

Copyright Wiley 2017.

This work is made available online in accordance with the publisher's policies. Please refer to any applicable terms of use of the publisher.

\section{General rights}

Copyright for the publications made accessible via the Queen's University Belfast Research Portal is retained by the author(s) and / or other copyright owners and it is a condition of accessing these publications that users recognise and abide by the legal requirements associated with these rights.

Take down policy

The Research Portal is Queen's institutional repository that provides access to Queen's research output. Every effort has been made to ensure that content in the Research Portal does not infringe any person's rights, or applicable UK laws. If you discover content in the Research Portal that you believe breaches copyright or violates any law, please contact openaccess@qub.ac.uk. 
Title:

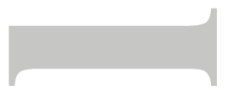

Authors:

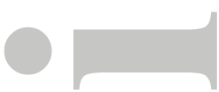

Affiliation:
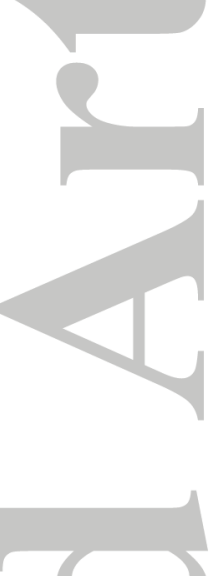

L. Winning ${ }^{1}$, L Meenan ${ }^{2}$

1 - Centre for Experimental Medicine, The Wellcome-Wolfson Institute for Experimental Medicine, School of Medicine, Dentistry and Biomedical Sciences, Queen's University Belfast, 97 Lisburn Road, Belfast, BT9 7BL, Northern Ireland (United Kingdom).

2 - Nanotechnology and Integrated Bioengineering Centre (NIBEC), School of Engineering, Ulster University, Shore Road, Newtownabbey, Co. Antrim, BT37 0QB, Northern Ireland (United Kingdom).

\section{* - Corresponding Author:}

Dr. Fionnuala T. Lundy

Centre for Experimental Medicine

The Wellcome-Wolfson Institute for Experimental Medicine

School of Medicine, Dentistry and Biomedical Sciences

Queen's University Belfast

97 Lisburn Road

Belfast

BT9 7BL

Northern Ireland

Email: f.lundy@qub.ac.uk

Phone: +44 (0)2890976387

This article has been accepted for publication and undergone full peer review but has not been through the copyediting, typesetting, pagination and proofreading process which may lead to differences between this version and the Version of Record. Please cite this article as an 'Accepted Article', doi: 10.1002/jbm.a.36044 


\begin{abstract}
Bioactive materials offer particular clinical benefits in the field of dental implantology, where differentiation of stem cells towards an osteoblastic lineage is required for osseointegration and appropriate function of implants in vivo. The aim of this study was to evaluate the osteoblastic response of Stro-1+ve periodontal ligament stem cells (PDLSCs) to three well-characterised biomaterial surfaces: an abraded titanium surface (cpTi) control; a polycrystalline titanium surface, with both micro and nano-topography produced by radio frequency magnetron sputtering (TiTi); and the same surface incorporating a sputter deposited calcium phosphate coating (CaP-TiTi). The CaP-TiTi surfaces were non-stoichiometric, carbonated, and calcium rich with a $\mathrm{Ca} / \mathrm{P}$ ratio of 1.74. PDLSCs were grown on each surface in the absence of supplementary osteogneic-inducing agents. Osteoblastic responses were assessed for up to 21 days in culture by measuring gene expression using real time q-PCR and via assessment of intracellular alkaline phosphatase (ALP) activity. Gene expression analysis for the CaP-TiTi surfaces showed a significant late stage up-regulation of Secreted Phosphoprotein 1. Additionally, there was a significant up-regulation of the Wnt signalling genes $\beta$-catenin and Wnt Family Member 5A on days 14 and 21 respectively for the CaP-TiTi surface. A significant increase in intracellular ALP at day 21 for the CaP-TiTi surface was also observed. These data suggest that the CaP-TiTi surfaces provide the bioactive conditions required for direct osteoblastic differentiation of PDLSCs.
\end{abstract}

\title{
Keywords
}

Periodontal ligament stem cells

Radio Frequency magnetron sputtering

Hydroxyapatite

Osteoblastic differentiation

Dental implants 


\section{Introduction}

Mesenchymal stem cells (MSCs) are recognised as offering much promise in the areas of tissue engineering and regenerative medicine due to their ability to be differentiated to specific tissue forming cell types. Intense research effort has been directed towards examining bone marrow mesenchymal stem cells (BMMSCs) for applications in bone-tissue engineering $(1,2)$. By contrast, periodontal ligament stem cells (PDLSCs) are a relatively more recently described population of MSCs and have been shown to be both highly proliferative and multipotent (3). PDLSCs also represent a promising source of stem cells owing to the relative ease in obtaining them compared with bone marrow harvesting. Within the field of dental implantology, PDLSCs have the potential to perform an important role during the osseointegration of devices when placed into fresh extraction sites (i.e. 'immediate' implant procedures). In addition, they also represent a source of stem cells for regenerative medicine applications, that could be applied around dental implants in areas where there is initially insufficient bone. Initial investigations have shown the potential of utilising PDLSCs to assess osteoblastic differentiation on various titanium surfaces (4-7). However, their behaviour in contact with bioactive materials such as hydroxyapatite (HA) and associated calcium phosphate $(\mathrm{CaP})$ systems is less well understood.

In general, in vitro investigations examining the osteoblastic response of MSCs from various sources use an 'osteogenic culture media' with chemical additives such as $\beta$-Glycerolphosphate employed as supplements to promote biochemically initiated osteoblastic differentiation. There is inherent ambiguity in such models as the associated osteoblastic phenotype that develops is not attributable to cell-substrate and/or cell-cell processes that normally regulate differentiation. Biomaterial surface-mediated events have previously been shown to directly trigger the commitment of undifferentiated cells toward an osteoprogenitor lineage and have been developed to

offer an alternative starting point for osteogenesis (8). Therefore, experimental models where surfaces that possess specific physical and chemical properties that can induce the osteoblastic 
differentiation of MSCs without the need for chemical supplementation in culture media are of increasing importance.

In this regard, specific forms of nanotopography created on titanium surfaces have been shown to induce direct osteoblastic differentiation in BMMSCs (9). Furthermore, augmentation of such nanotopography with a bioactive chemistry, specifically that provided by $\mathrm{HA}$ and other $\mathrm{CaP}$ systems, has been shown to provide significant benefits in terms of enhanced osteoblastic differentiation $(10,11)$. HA has the potential to induce both osteoconductive, and osteoinductive cell responses and therefore represents a well-established platform to deliver the appropriate surface cues for direct stem cell differentiation (12). In order to produce specific titanium nanotopography and attendant $\mathrm{CaP}$ surface chemistry properties a range of deposition techniques have been investigated including plasma spraying, pulse laser deposition (PLD), and radio frequency (RF) magnetron sputtering. RF magnetron sputtering, in particular, has been proven to be a particularly effective technique in this regard. Using appropriate titanium and hydroxyapatite sputter target materials provides for a $\mathrm{Ti}$ layer with a form of polycrystalline nanotopography and a CaP coating both as individual surfaces and in combination, i.e. bioactive $\mathrm{CaP}$ on $\mathrm{Ti}$ nanotopography. By varying the deposition parameters, the interface between the substrate and the coating can be manipulated to provide the conditions necessary for direct MSC differentiation (13). To date, most of the work in this area has focused on the application of RF magnetron sputtered $\mathrm{Ti} / \mathrm{CaP}$ for control of the behaviour of BMMSCs (11). Hence, the utilisation of RF magnetron sputtered Ti/CaP surfaces to manipulate and understand PDLSC behaviour is novel.

The central aim of this study is to examine the osteoblastic response of PDLSCs to three titanium test surfaces: an abraded titanium control surface (cpTi); a polycrystalline titanium surface, with both micro and nano-topography produced by radio frequency magnetron sputtering (TiTi); and the same surface incorporating a sputter deposited calcium phosphate coating (CaP-TiTi). In particular, the work reported here focuses on the delivery of surfaces with specific nanotopography and chemistry that have proven effectiveness for the direct (surface mediated) differentiation of stem 
cells. All of the surfaces produced were characterised in detail using Fourier Transform Infrared Spectroscopy (FTIR), X-ray Diffraction (XRD), X-Ray Photoelectron Spectroscopy (XPS), and Atomic Force Microscopy (AFM), in order to fully define the topography and surface chemistry created. The PDLSCs were cultured on the surfaces in the absence of any osteogenic supplement in the growth media. Osteoblastic responses were assessed for up to 21 days in vitro by measurement of real time q-PCR gene expression of alkaline phosphatase (ALPL), collagen type I alpha I (COL1A1), runt-related transcription factor (RUNX2) and secreted phosphoprotein 1 (SPP1). Additionally, Wnt signalling pathways were assessed by measuring gene expression for $\beta$-catenin (CTNNB1) and Wnt Family Member 5A (WNT5A). Functional assessment of intracellular alkaline phosphatase (ALP) enzyme activity was also carried out. To the best of the authors' knowledge, this represents the first significant report of osteogenic differentiation of PDLSCs to these specifically defined surface cues in the absence of biochemical supplementation of media with osteogenic factors.

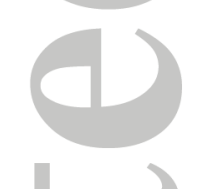

\subsection{Materials and Methods}

\subsection{Sample Preparation}

For this study $15 \mathrm{~mm} \times 15 \mathrm{~mm}$ x $0.5 \mathrm{~mm}$ coupons of chemically pure titanium (cpTi), (Titanium International Ltd, UK) were abraded using a succession of 800, and 1200 grade SiC papers in order to prepare the surfaces to a consistent finish. The coupons were twice sonicated for ten minutes each in acetone, isopropyl alcohol and distilled deionised water. The abraded coupons were then dried thoroughly in a convection oven at $70^{\circ} \mathrm{C}$ for twelve hours. From these samples, a range of different surfaces were prepared using RF magnetron sputtering. As detailed in Table 1, the final

sample types were abraded and cleaned chemically pure titanium surfaces (cpTi); polycrystalline titanium coated on the cpTi surfaces (TiTi); and calcium phosphate sputter coated onto the TiTi surfaces from a hydroxyapatite target (CaP-TiTi). 


\subsection{Sputtering Procedure}

For details of sputtering procedure see Supplementary information S1.

\subsection{Characterisation of the Ca-P Powders and Coatings}

FTIR spectroscopy was carried out using a Varian 640-IR series instrument with a PIKE Diffuse Reflectance Infrared Fourier Transform Spectroscopy (DRIFTS) accessory. Samples were analysed in absorbance mode from $4000-400 \mathrm{~cm}^{-1}$ at a resolution of $4 \mathrm{~cm}^{-1}$ with 20 scans collected per sample. XRD was carried using a Bruker D8 Discover Diffractometer fitted with a Gobel Mirror. A $\mathrm{Cu} \mathrm{K \alpha} \mathrm{X-ray} \mathrm{radiation}(\lambda=1.540 \AA)$ source was employed with diffraction scans obtained at a tube voltage of $40 \mathrm{kV}$ and a current of $40 \mathrm{~mA}$. Scans were recorded from $20-50^{\circ} 2 \theta$ with a step size of $0.04^{\circ}$ and a dwell time of 30 seconds. For the grazing incidence angle XRD studies of CaP coatings on the cpTi substrates the tube angle was set to $0.75^{\circ}$. XPS was carried out using a Kratos Axis Ultra DLD spectrometer. Spectra were recorded employing monochromated Al Ka X-rays (hv= 1486.6 electron volts $(\mathrm{eV})$ ) with the anode operating at $10 \mathrm{kV}$ and $15 \mathrm{~mA}(150 \mathrm{~W})$. The base pressure was $1.33 \times 10^{-7} \mathrm{~Pa}$ and the operating pressure was $6.66 \times 10^{-7} \mathrm{~Pa}$. A hybrid lens mode was employed during analysis (electrostatic and magnetic), with an analysis area of approximately 300 $\mu \mathrm{m} \times 700 \mu \mathrm{m}$ and a take-off angle (TOA) of $90^{\circ}$ with respect to the sample surface normal. Wide energy survey scans (WESS) were obtained at a pass energy of $160 \mathrm{eV}$. High resolution spectra were recorded for $\mathrm{C} 1 \mathrm{~s}, \mathrm{O} 1 \mathrm{~s}, \mathrm{Ca} 2 \mathrm{p}, \mathrm{P} 2 \mathrm{p}$ and Ti2p at a pass energy of $20 \mathrm{eV}$. The Kratos magnetic lens charge neutraliser system was used on all samples operating with a filament current of 1.952.00 A and a charge balance of between 3.3 and 3.5 V. Sample charging effects on the measured $\mathrm{BE}$ positions were further corrected by setting the lowest $\mathrm{BE}$ component of the $\mathrm{C} 1 \mathrm{~s}$ spectral envelope to $285.0 \mathrm{eV}$, i.e. the value generally accepted for adventitious carbon surface contamination (14). Photoelectron spectra were further processed by subtracting a linear background and using the peak area for the most intense spectral line of each of the detected elemental species to determine the $\%$ atomic concentration. 
The surface topography was evaluated using a Digital Instruments Dimension 3000 Scanning Probe Microscope (SPM). The surface was scanned in tapping mode over $10 \mu \mathrm{m}$ x $10 \mu \mathrm{m}$ area using a force modulated etched silicon probe (FESP) with a nominal force constant of $0.28 \mathrm{~N} \mathrm{~m}^{-1}$. A high frequency $(75 \mathrm{kHz})$ z-oscillation was imposed upon the probe during $\mathrm{x}-\mathrm{y}$ raster scanning, which provides for intermittent contact between the probe and the sample surface. This eliminates shear forces because the probe is not in constant contact with the sample. The images were collected as false colour plots and subjected to minimal computational manipulation, allowing only for a tilt removal.

\subsection{In vitro analysis}

2.4.1 Explant procedure and isolation of periodontal ligament stem cells

Ethical approval was granted for the collection of teeth from the School of Dentistry, Belfast Health and Social Care Trust by the Office for Research Ethics Northern Ireland, (Approval Number 08/NIR03/15). See supplementary information $S 2$ for explant method and stem cell isolation.

2.4.2 Osteogenic gene expression of PDLSCs on test surfaces

To investigate the effect on osteoblastic gene expression from PDLSCs in contact with the various samples, cells were seeded in triplicate on each of the test surfaces at a density of $1 \times 10^{4} / \mathrm{ml}$. At days $7,14, \& 21$ coupons were carefully removed from their culture well and rinsed twice with cold phosphate-buffered saline. RNA was extracted using a RNeasy mini kit (Qiagen, UK) according to the manufacturer's instructions. RNA yield and purity was assessed on a Take3 plate (BioTek, USA). Following this, cDNA was synthesised using the SuperScript vilo cDNA synthesis kit (Invitrogen, UK). The prepared cDNA was subsequently frozen $\left(-80^{\circ} \mathrm{C}\right)$. Real-time qPCR for ALPL, COL1A1, RUNX2, and SPP1 was carried out on a Stratagene PCR machine (Agilent Technologies). Normalisation of results was achieved utilising the house-keeping genes Beta-2 microglobulin (B2M) and glucuronidase beta (GUSB) and deriving the geometric mean of these. Primer information is listed in Table 2. Sequence amplification was performed as follows: denaturation at $55^{\circ} \mathrm{C}$ for 2 minutes and $95^{\circ} \mathrm{C}$ for 10 minutes followed by 45 cycles of $95^{\circ} \mathrm{C}$ for 30 
seconds and $50^{\circ} \mathrm{C}$ for 1 minute. The relative gene expression was calculated by the $2^{-\Delta \Delta \mathrm{CT}}$ method. Results are reported as fold change of gene expression compared with the Ti surface (cpTi) at day 7, which was used in all experiments as the control value.

\subsubsection{Wnt signalling pathway gene expression of PDLSCs on test surfaces}

Similarly, to the protocol described in 2.4.2., real-time qPCR was used to investigate potential activation of Wnt signalling pathways by studying gene expression of CTNNB1 (canonical pathway) and WNT5A (non-canonical pathway). Primer information is listed in Table 2. Gene expression was measured for the three test surfaces towards the later stages of differentiation on days 14 and 21. Normalisation of results was again achieved utilising the house-keeping genes B2M and GUSB. Results are reported as fold change of gene expression compared with the cpTi surface at day 14 .

\subsubsection{Alkaline phosphatase (ALP) activity of PDLSC on test surfaces}

To further assess the development of an osteoblastic phenotype from PDLSCs grown on the three test surfaces (cpTi, TiTi, CaP-TiTi), an ALP activity assay was performed on days 7, 14, and 21 . Briefly, $1 \times 10^{4} / \mathrm{ml}$ PDLSCs were seeded in triplicate on each test surface. At each time point the coupons were carefully removed from their wells and put into a fresh 12 -well plate, to avoid including cells growing around but not on the coupons. Surfaces were rinsed with PBS twice, and then lysed using $150 \mu 1$ of lysis buffer $(0.2 \%$ Triton X-100), followed by a 15 -minute incubation period at $37^{\circ} \mathrm{C}$. The surfaces were then scraped to remove the lysed cells, which were then transferred to $1.5 \mathrm{ml}$ tubes before vortexing and centrifugation at $4^{\circ} \mathrm{C}$ for 10 minutes. Supernatants were collected for quantification of ALP activity (Sigma-Aldrich, UK). ALP activity was normalized to total protein content, measured using a BCA protein assay kit (Pierce, Rockford, IL, USA), and the results were expressed as $\eta \mathrm{mol} \mathrm{PNPP} / \mathrm{min} / \mathrm{mg}$ protein.

\subsubsection{Statistical Analysis}

As indicated, all experiments were carried out in triplicate and results represent two independent experiments. Data points were analysed at $7,14, \& 21$ days. One-way analysis of variance was used 
to determine statistical significance between gene expression for the samples and a Tukey post hoc test was used to determine significance between pairs of sample means. ALP activity data was analysed by the Kruskal-Wallis test for independent samples, followed by Dunn's test for multiple comparisons. The level of statistical significance was set at $\mathrm{p}<0.05$. The statistical analyses were performed with IBM SPSS Statistics for Windows (IBM Corp. Released 2012. Version 21.0.

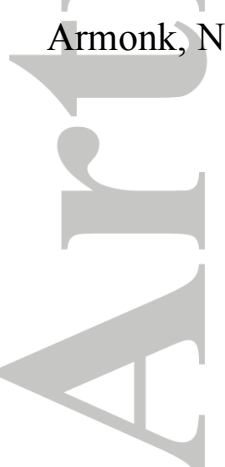

\subsection{Results}

\subsection{Characterisation of the Ca-P Precursor Powders}

The HA target precursor powder was characterized using FTIR, XRD and XPS to determine the nature of the material prior to sputter deposition of the $\mathrm{CaP}$ coatings used in this study. The results obtained were comparable to those described previously for similar HA powders (15). From these findings it is clear that the purity, crystallinity and stoichiometry of the powder was as expected and confirmed the material was a carbonated from of HA.

\subsection{Characterisation of the Surfaces}

The FTIR spectrum for a CaP coating sputtered from HA target is shown in Figure 1. Well resolved P-O stretching vibrations were observed as expected between $1100-950 \mathrm{~cm}^{-1}$. O-P-O bending vibrations are also present between $620-560 \mathrm{~cm}^{-1}$. Hydrogen phosphate bands $\left(\mathrm{HPO}_{4}{ }^{2-}\right)$ can also be observed at 1122 and $582 \mathrm{~cm}^{-1}(16)$. A very weak O-H libration band is observed around $632 \mathrm{~cm}^{-}$

${ }^{1}$ as a weak shoulder, with a further peak associated with $\mathrm{O}-\mathrm{H}$ groups observed at $3570 \mathrm{~cm}^{-1}$. This peak may be associated with $\mathrm{O}-\mathrm{H}$ stretching groups within the film (16). The absence of strong -OH functional groups, commonly observed at approximately $632 \mathrm{~cm}^{-1}$ and $3568 \mathrm{~cm}^{-1}$, indicate that a degree of dehydroxylation has occurred within the CaP crystal structure deposited from the HA 
target under the conditions employed here. Peaks indicative of $\mathrm{CO}_{3}{ }^{2-}$ species were also observed in the FTIR spectrum for Ca-P coating between $1550-1400 \mathrm{~cm}^{-1}$.

The XRD pattern for the control substrate (cpTi) after abrasion was consistent with that observed for the International Centre for Diffraction Data (ICDD) file \#44-1294 for titanium, as shown in Figure 2(a). The most intense peaks were observed at $35.3^{\circ}, 38.5^{\circ}$ and $40.3^{\circ} 2 \theta$ and relate to the 100, 002 and 110 reflections, respectively. The XRD pattern for the titanium layer sputter deposited onto the cpTi substrate (TiTi), as shown in Figure 2(b) had diffraction peaks in similar $2 \theta$ positions, however, this layer exhibits a clear 002 preferred orientation due to the relative intensity of the peak at $38.5^{\circ} 2 \theta$ which dominates the diffraction pattern. The corresponding diffraction pattern for the CaP coating, as shown in Figure 2(c), has peaks that are clearly indicative of HA, with $2 \theta$ values that correspond closely to those observed in the ICDD file \#09-0432 for HA. The four strongest peaks are observed at $25.9^{\circ}, 31.7^{\circ}, 32.1^{\circ}$ and $32.8^{\circ} 2 \theta$, and correspond to $002,210,211$ and 112 reflections, respectively. The 002 reflection at $25.9^{\circ} 2 \theta$ dominates the diffraction pattern, which suggests that this coating has a 002 preferred orientation as clearly observed in Figure 2(d). Peaks indicative of the underlying titanium layer are also present at $2 \theta$ values of $35.3^{\circ}, 38.5^{\circ}$ and $40.3^{\circ} 2 \theta$, (17) as per the ICDD file \#44-1294 for titanium.

The XPS data are shown in Figures 3, 4, \& 5. For the cpTi surface after abrasion indicates the presence of oxygen, carbon and nitrogen in addition to titanium. The high-resolution Ti2p spectrum confirms the presence of $\mathrm{TiO}_{2}$ due to the peaks at $458.6 \mathrm{eV}\left(\mathrm{Ti} 2 \mathrm{p}_{3 / 2}\right)$ and $464.5 \mathrm{eV}\left(\mathrm{Ti} 2 \mathrm{p}_{1 / 2}\right)(17$, 18). In addition, the peak observed at $453.5 \mathrm{eV}\left(\mathrm{Ti} 2 \mathrm{p}_{3 / 2}\right)$ would normally be associated with metallic titanium $(18,19)$. The presence of a surface oxide layer is further confirmed by the nature of the high-resolution O1s spectral envelope, which clearly shows a strong contribution from $\mathrm{TiO}_{2}$ at $530.4 \mathrm{eV}$. The contribution on the high B.E. side of the $\mathrm{O} 1 \mathrm{~s}$ peak at $530.4 \mathrm{eV}$ may be a consequence of the presence of oxygen from organic species and/or $\mathrm{OH}$ groups $(17,18)$. Similar results were observed for the sputter deposited titanium layer (TiTi). However, in this case the contribution from the $\mathrm{TiO}_{2}\left(459.0 .0 \mathrm{eV}\left(\mathrm{Ti} 2 \mathrm{p}_{3 / 2}\right)\right.$ and at $\left.464.7 \mathrm{eV}\left(\mathrm{Ti} 2 \mathrm{p}_{1 / 2}\right)\right)$ is more dominant than 
that for the metallic state in the Ti2p high-resolution spectral envelope (which was not detected here). The XPS WESS and high-resolution scans for a CaP-TiTi surfaces, shows peaks corresponding to Ca2s $(439.0 \mathrm{eV}), \mathrm{Ca} 2 \mathrm{p}_{3 / 2}(347.6 \mathrm{eV}), \mathrm{Ca} 2 \mathrm{p}_{1 / 2}(351.1 \mathrm{eV}), \mathrm{Ca} 3 \mathrm{~s}(44.3 \mathrm{eV}), \mathrm{P} 2 \mathrm{p}$ (133.6 eV), P2s (190.9 eV), O1s $(531.6 \mathrm{eV})$ and $\mathrm{O}_{\mathrm{KLL}}$ Auger peak $(978.0 \mathrm{eV})$. The key peak positions are highlighted in Table 3 and correspond closely to those reported for HA in the literature (14). The $\mathrm{Ca} / \mathrm{P}$ ratio for the $\mathrm{CaP}$ coating was $1.74 \pm 0.14$, as reported in Table 4, which is in close agreement with that expected for stoichiometric HA (1.67).

AFM analysis of the cpTi surface after abrasion indicates the presence of random abrasion scratches running across its surface. These features dominate the substrate surface and range in width from $0.5-2.0 \mu \mathrm{m}$. Small hillocks, pits and fissures, which vary in size up to $5.0 \mu \mathrm{m}$, are also seen regularly across the surface, particularly between the abrasion scratches, as shown in Figure 6(a). For TiTi surface, titanium crystallites of $0.39 \pm 0.05 \mu \mathrm{m}$ in diameter were observed across the surface and seem to have formed preferentially around the more prominent surface asperities on the substrate, as illustrated in Figure 6(b). These surface features were seen to range between $0.25-0.5$ $\mu \mathrm{m}$. It is also apparent that there has been significant in-filling of the larger pits and abrasion scratches on the substrate surface by the sputtered Ti layer as observed by a decrease in the surface roughness values when compared to those obtained for the control cpTi surface, as highlighted in Table 5. The sputter deposited $\mathrm{CaP}$ coating on the TiTi surface exhibits more regular sized columnar features across the coating surface of diameter $0.32 \pm 0.07 \mu \mathrm{m}$. These features were found to range from $0.2-0.43 \mu \mathrm{m}$ in diameter. Again, the surface roughness for the CaP-TiTi surfaces was again seen to decrease with further apparent in-filling of the pits and abrasion scratches on the substrate surface.

\subsection{In Vitro Results}

3.3.1 Osteogenic gene expression analysis

The osteogenic phenotype of the PDLSCs following culture on each of the three surfaces was confirmed at the transcriptional level by genes encoding ALP, COL1A1, RUNX2, and SPP1. 
Figure 7 shows the fold change in gene expression for each gene relative to that for cpTi surface at Day 7 which was used as a calibration value. For ALPL there was up-regulation for PDLSCs cultured on both the cpTi surface and CaP-TiTi at day 14. This was followed by a significant downregulation for the CaP-TiTi surface by day 21, whereas the cpTi surface continued to exhibit further up-regulation of ALPL. Despite the fact that the fold changes in gene expression were generally lower for COL1A, significant differences in expression were observed across all three time points. RUNX2 also displayed relatively low fold changes, with significant differences between the surfaces only seen at day 21 . The largest fold change value was observed for the SPP1 gene, where there was a significant up regulation of x16.9 for the CaP-TiTi surface at day 21.

3.3.2 Wnt signalling pathways, gene expression.

Wnt signalling was investigated at the transcriptional level by the genes encoding CTNNB1 for the canonical pathway, and WNT5A for the non-canonical pathway at days 14 and 21. Figure 8 shows the fold change in gene expression for each gene relative to that of the cpTi surface at Day 14 which was used as a calibration value. A significant upregulation was observed for both CTNNB1 and WNT5A genes on the CaP-TiTi surface at days 14 and 21 respectively.

\subsubsection{Alkaline Phosphatase Activity}

At days 7 and 14 there was no significant difference between ALP activity on any of the three test surfaces compared to the control (Figure 9). However, a significantly higher degree of ALP activity was observed for the CaP-TiTi surface by day 21 when compare to the cpTi and TiTi surfaces. 


\subsection{Discussion}

The differentiation of mesenchymal stem cells (MSCs) to various lineages can be modulated by a variety of signals including chemical cues, biomechanical cues, and biophysical cues. Studies investigating the influence of biophysical cues, specifically micro- and nano-topography, have demonstrated the robust role this effect has on dictating the cell fate (19). Surfaces which incorporate both chemical and physical properties are of increasing interest as they offer the potential to engender responses for specific cell applications (20). In this study we examined the response of PDLSCs to three test surfaces: an abraded titanium surface (cpTi) control; a polycrystalline titanium surface, with both micro and nano-topography produced by radio frequency magnetron sputtering (TiTi); and the same surface incorporating a sputter deposited calcium phosphate coating (CaP-TiTi).

The cpTi control surface is a physically abraded surface, which incorporates pits, fissures and hillocks with features that were up to $5.0 \mu \mathrm{m}$ across as indicated by AFM analysis. XRD and XPS analysis confirmed that these surfaces were indeed pure titanium and contained no detectable impurities. The corresponding TiTi surface, which incorporated sputtered deposited polycrystalline titanium, had the effect of reducing the surface roughness, indicating that in-filling of the surface occurs as a consequence of the sputtering process. In addition, micro-crystallites of titanium in the range $0.25-0.5 \mu \mathrm{m}$ across are visible right across the surface, particularly around surface asperities, where the surface energy will be lower. XPS showed that the $\mathrm{TiO}_{2}$ contribution here is more dominant than that from the source metal. Low levels of nitrogen were also seen to be present on this surface. XRD highlights that the TiTi surface exhibits a clear 002 preferred orientation. These results suggest that although the TiTi surface is predominantly titanium, its surface chemistry and topography is different than that of the cpTi control material. The CaP-TiTi surface had a much reduced surface roughness compared to either the cpTi and TiTi samples. The micro-crystallites seen for the TiTi surface again occur homogeneously across the entire sample confirming that the $\mathrm{CaP}$ coating conforms to the this polycrystalline topography (21). It should also be noted that the 
$\mathrm{CaP}$ coatings were thermally annealed to $500^{\circ} \mathrm{C}$, as coatings sputter deposited under the conditions employed here are typically amorphous in nature, and inherently physiologically unstable (14). The chemistry of the sputtered CaP detected here reflects the low sputtering power employed (150W), as such coatings have been shown to contain only HA-like properties with no other additional $\mathrm{CaP}$ phases or by-products presence (16). This means that this coating is consistent with the requirements of various international standards (ASTM 1185-03(2014), ASTM 1609 - (08)2014 and ISO 13779 (Parts 2 and 3)). The $\mathrm{Ca} / \mathrm{P}$ ratio of the CaP-TiTi sample was determined to be $1.74 \pm$ 0.14 , which is slightly higher than would be expected for pure hydroxyapatite (1.67). FTIR analysis highlighted that there had been hydrogenation of the phosphate functional groups in the Ca-P films with concurrent dihydroxylation. It is suggested that this has a significant influence on the atomic ordering in the $\mathrm{CaP}$ coating that is still inherent event after thermal annealing (14). A significant reduction in $\mathrm{OH}^{-}$groups means that the charge balance necessary within the crystal structure must therefore be provided by other means. HA (and $\mathrm{CaP}$ coatings) can undergo carbonate $\left(\mathrm{CO}_{3}{ }^{2-}\right)$ substitution within the crystal lattice at multiples sites. Most notably, A-type substitution for $\mathrm{OH}^{-}$ groups, B-type substitutions for $\mathrm{PO}_{4}{ }^{3-}$ groups, or both $(\mathrm{AB})$ substitution are acknowledged as providing for charge balance in the lattice structure of HA $(21,22)$. It is now widely accepted that in natural apatite, B-type substitutions dominate (21). Evidence for some degree of $\mathrm{CO}_{3}{ }^{2-}$ substitution here is suggested by the presence of these peaks between $1550-1400 \mathrm{~cm}^{-1}$ in the FTIR spectrum (Figure 1). No evidence for the presence of $\mathrm{CaO}, \mathrm{Ca}(\mathrm{OH})_{2}$ or $\mathrm{CaCO}_{3}$ was found in the XRD, FTIR or XPS analyses. Therefore, the CaP coatings produced here can be said to resemble something close to naturally occurring apatite rather than synthetic HA in that they contain carbonate and are both dehydroxylated and non-stoichiometric (23). Furthermore, it is assumed that the material deposited here is not a calcium deficient hydroxyapatite (CDHA) material $\left[\mathrm{Ca}_{10-\mathrm{X}}\right.$ $\left.\left[\left(\mathrm{PO}_{4}\right)_{6-\mathrm{X}}\left(\mathrm{HPO}_{4}\right)_{\mathrm{X}}\right](\mathrm{OH})_{2-\mathrm{X}}\right]$, as this would result in $\mathrm{Ca} / \mathrm{P}$ ratio less than 1.67 (21). Furthermore, the presence of $\mathrm{CO}_{3}{ }^{2-}$ is not seen in the CDHA system. The $\mathrm{CO}_{3}{ }^{2-}$ and $\mathrm{HPO}_{4}{ }^{2-}$ can occur either as substitutional ions in the lattice of the coatings obtained (or as labile materials), or both. The XRD 
results also show that the CaP-TiTi surface has a preferred 002 c-axis orientation. There is also a change in the relative peak intensities of the 211 and 112 peaks as would be expected for stoichiometric HA (Figures 2(c) and (d)). These observations are in line with previous studies on sputter deposited apatites (18). Other work has also shown that a preferred 002 orientation in $\mathrm{CaP}$ coatings can enhance the cellular response in vitro (13), in particular for MSCs (24). It has also been reported that the bioactivity attributed to $\mathrm{CaP}$ materials originates due to the actions of free $\mathrm{Ca}^{2+}$ ions (25). Based on these various observations, it is suggested that a possible formula for the coatings produced here is $\left.\mathrm{Ca}_{10-\mathrm{X}-\mathrm{Y} / 2}\left[\mathrm{HPO}_{4}\right)\left(\mathrm{PO}_{4}\right)\right]_{6-\mathrm{X}-\mathrm{Y}}\left(\mathrm{CO}_{3}\right)_{\mathrm{Y}}(\mathrm{OH})_{2-\mathrm{X}}(26)$. However, the possibility of labile $\mathrm{CO}_{3}{ }^{2-}$ and $\mathrm{HPO}_{4}{ }^{2-}$ occurring in the lattice of the $\mathrm{CaP}$ coating cannot be discounted (27).

The biological analysis of PDLSCs cultured on the CaP-TiTi surface showed that this surface is capable of inducing osteogenic differentiation, as evidenced by both gene expression and ALP activity compared to the cpTi control. The osteogenic differentiation observed here is thus attributable to the attendant surface chemistry and topography. The role of the CaP is clearly marked here by the fact there was little appreciable difference observed between the PDLSC response to TiTi surface and the cpTi, control. In this regard, the presence of titanium dioxide $\left(\mathrm{TiO}_{2}\right)$ which has been shown previously to enhance the osteoblast response of MSCs (compared to pure titanium surfaces) (28), was not apparent in the in vitro results obtained here. Moreover, given the similar surface features observed for the CaP-TiTi and TiTi surfaces, it would again suggest that the role of the $\mathrm{CaP}$ chemistry is the most significant factor in attaining an osteogenic response from the PDLSCs.

Undifferentiated mesenchymal stem cells tend to show weak alkaline phosphatase activity, whereas fully differentiated osteoblasts have higher activity. ALP may regulate the degradation of inorganic pyrophosphate providing sufficient local concentration of phosphate for mineralization (29). Our results indicate that PDLSCs growing on the CaP-TiTi surface showed significantly higher ALP activity levels at day 21 compared to either the cpTi and TiTi surfaces. At the gene level, the ALPL gene codes for the production of alkaline phosphatase. The up regulation of alkaline 
phosphatase is generally regarded as an early marker of osteogenic differentiation. For example, Kulterer et al. observed that in the osteogenic differentiation of BMMSCs, up regulation of ALPL commenced on day 4 , but by day 14 down regulation occurs as the cells start to enter the mineralization phase of phenotype change (30). Similar behaviour was observed in this study were up regulation of ALPL at day 14 was followed by a significant down regulation at day 21 days for PDLSCs cultured on CaP-TiTi. By comparison, the cpTi control and TiTi surfaces showed up regulation at each time point. When these results are viewed in the context of the associated increase in functional ALP enzyme activity for PDLSCs seeded on the CaP-TiTi surface, it suggests that they are further along the osteogenic differentiation pathway by day 21 .

The SPP1 gene (also known as Osteopontin or Bone Sialoprotein 1), codes for a secreted protein which binds hydroxyapatite with high affinity. It is generally considered a late marker of osteogenic differentiation, although its expression is known to peak twice: firstly around day 4 during proliferation and secondly between days 14-21 during mineralization (31). In this study we observed a 17 fold increase in the expression of SPP1 by Day 21 for PDLSCs cultured on the CaPTiTi surface. This again suggests that cells are entering a mineralisation stage of differentiation.

In addition to surface topographical cues, one of the important factors regulating cellular response is material solubility. This determines the type and concentration of dissolved ions in the cell environment. Previous work has shown that RF magnetron sputtering of hydroxyapatite onto titanium results in 'as-deposited' coatings that are typically non-stoichiometric, with slightly $\mathrm{Ca}^{2+}$ rich surfaces (17). Although the CaP surfaces here were thermally annealed to reduce their inherent solubility, it is still likely that some moderate dissolution occurs. This, in combination with the apparent 002 preferred orientation of the CaP coating produces a surface that is capable of releasing $\mathrm{Ca}^{2+}$ ions, known to play an important role in cell proliferation and differentiation, into the localised ECM/media $(32,33)$. Combining this with the micro- and nano-scale surface features that are produced by sputtering, offers a means for greater physical interaction between the cells and the CaP-TiTi surface. 
RUNX2 is acknowledged as the central control gene within the osteoblast phenotype (34). At early stage differentiation RUNX2 plays a major role in directing MSCs to the osteoblast lineage and triggering the expression of many extracellular bone matrix proteins (35). At Day 21 in this study there was only modest upregulations of x1.7 and x1.4 fold changes for the cpTi and the CaP-TiTi surfaces, respectively. Previous studies investigating RUNX2 expression have included an earlier time point, i.e. at days 1,3 or 4 (36-38). The inclusion of earlier time points in the present study may have provided a better baseline and more meaningful comparison of fold change analysis for RUNX2. Similarly, analysis of the COL1A1 expression showed only minor differences in fold changes. COL1A1 codes for production of type I collagen and plays an important role in cell adhesion, proliferation and differentiation of the osteoblast phenotype. It is considered to be an early marker of osteoprogenitor cells (39) and thus inclusion of an earlier time point for this gene may have allowed a more definitive conclusions to be drawn.

Previous work has shown that Wnt signalling through the canonical and non-canonical pathways modulate multiple aspects of osteoblast physiology including proliferation, differentiation, bone matrix formation, and apoptosis (40). Significant upregulation was observed for both CTNNB1 and WNT5A genes on the CaP-TiTi surface at days 14 and 21 respectively. This would suggest the enhanced osteoblastic response of the CaP-TiTi surface is likely occurring through these Wnt signalling pathways (both canonical and non-canonical). This finding is in agreement with a previous study which showed modifying the physical and chemical properties of titanium surfaces could differentially effect the expression of osteo-modulatory molecules in PDLSCs grown on them (41). By carefully characterizing surfaces using the RF sputtering technique in the present study, we for the first time were able to demonstrate that it is the additional chemistry of $\mathrm{CaP}$ on nanotopographic surfaces (CaP-TiTi) rather than nano-topographic features alone (TiTi) that is key in generating the direct osteoblastic differentiation of PDLCSs in vitro. 


\subsection{Conclusion}

The CaP-TiTi surface directly promoted the osteogenic differentiation of PDLSCs in the absence of osteogenic inducing factors in the culture media. Differences in gene expression behaviour associated with the osteogenic differentiation of the stem cells over a 21-day culture period were observed to be statistically significant on the CaP-TiTi surface when compared to both cpTi and TiTi samples. This was supported by in vitro analysis of ALP expression activity. Analysis of the CaP-TiTi surfaces indicate that it was comprised of a non-stoichiometric, carbonated, calcium rich $(\mathrm{Ca} / \mathrm{P}$ ratio: 1.74$)$ surface chemistry and that it is these properties which was likely to have been the key factors in driving the PDLSC down the osteoblastic differentiation pathway. Moreover, the data attained suggest that under the specific conditions applied, the topography present on the TiTi surface is not capable of directly providing an osteogenic response on its own. Hence, it has been shown here for the first time sputter deposited CaP coatings deposited on micro/nano-scale titanium topography can directly induce PDLSCs to an osteoblast cell lineage. These results support the promise of such surfaces for both the incorporation on dental device surface and as a means to create osteogenic cells for enhanced implant fixation with appropriate in vivo studies now required to confirm this enhanced osteogenic and regenerative potential.

\section{Acknowledgements}

The authors would like to acknowledge the $\mathrm{PhD}$ funding provided by of the Department of Employment and Learning (Northern Ireland), and the Northern Ireland Medical and Dental Training Agency (NIMDTA) in supporting this work.

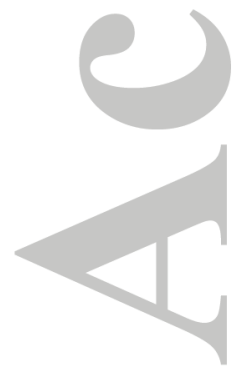




\section{References}

1. Olivares-Navarrete R, Hyzy SL, Park JH, Dunn GR, Haithcock DA, Wasilewski CE, et al. Mediation of osteogenic differentiation of human mesenchymal stem cells on titanium surfaces by a Wnt-integrin feedback loop. Biomaterials. 2011 Sep;32(27):6399-411.

2. Rausch-fan X, Qu Z, Wieland M, Matejka M, Schedle A. Differentiation and cytokine synthesis of human alveolar osteoblasts compared to osteoblast-like cells (MG63) in response to titanium surfaces. Dent Mater. 2008 Jan;24(1):102-10.

3. Seo BM, Miura M, Gronthos S, Bartold PM, Batouli S, Brahim J, et al. Investigation of multipotent postnatal stem cells from human periodontal ligament. Lancet. 2004 Jul 1016;364(9429):149-55.

4. Heo YY, Um S, Kim SK, Park JM, Seo BM. Responses of periodontal ligament stem cells on various titanium surfaces. Oral Dis. 2011 Apr;17(3):320-7.

5. Kim SY, Yoo JY, Ohe JY, Lee JW, Moon JH, Kwon YD, et al. Differential expression of osteomodulatory molecules in periodontal ligament stem cells in response to modified titanium surfaces. Biomed Res Int. 2014;2014:452175.

6. Li X, Liao D, Gong P, Dong Y, Sun G. Biological behaviour of neur2ally differentiated periodontal ligament stem cells on different titanium implant surfaces. J Biomed Mater Res A. 2014 Aug;102(8):2805-12.

7. Gao H, Li B, Zhao L, Jin Y. Influence of nanotopography on periodontal ligament stem cell functions and cell sheet based periodontal regeneration. Int J Nanomedicine. 2015 Jun 19;10:400927.

8. Albrektsson T, Johansson C. Osteoinduction, osteoconduction and osseointegration. Eur Spine J. 2001 Oct;10 Suppl 2:S96-101.

9. Olivares-Navarrete R, Hyzy SL, Hutton DL, Erdman CP, Wieland M, Boyan BD, et al. Direct and indirect effects of microstructured titanium substrates on the induction of mesenchymal stem cell differentiation towards the osteoblast lineage. Biomaterials. 2010 Apr;31(10):2728-35.

10. Sjöström T, Brydone AS, Meek RD, Dalby MJ, Su B, Mcnamara LE. Titanium nanofeaturing for enhanced bioactivity of implanted orthopedic and dental devices. Nanomedicine. 2013;8(1):89104.

11. McCafferty MM, Burke GA, Meenan BJ. Mesenchymal stem cell response to conformal sputter deposited calcium phosphate thin films on nanostructured titanium surfaces. J Biomed Mater Res Part A. 2014;102(10):3585-97.

12. Lobo SE, Glickman R, da Silva WN, Arinzeh TL, Kerkis I. Response of stem cells from different origins to biphasic calcium phosphate bioceramics. Cell Tissue Res. 2015

Aug;361(2):477-95.

13. Boyd AR, O'Kane C, O'Hare P, Burke GA, Meenan BJ. The influence of target stoichiometry on early cell adhesion of co-sputtered calcium-phosphate surfaces. J Mater Sci Mater Med. 2013 Dec;24(12):2845-61. 
14. Boyd AR, Meenan BJ, Leyland NS. Surface characterisation of the evolving nature of radio frequency (RF) magnetron sputter deposited calcium phosphate thin films after exposure to physiological solution. Surf Coat Technol. 2006;200(20-21):6002-13.

15. O'Kane C, Duffy H, Meenan BJ, Boyd AR. The influence of target stoichiometry on the surface properties of sputter deposited calcium phosphate thin films. Surf Coat Technol. 2008;203(12):121-8.

16. Boyd AR, Rutledge L, Randolph LD, Mutreja I, Meenan BJ. The deposition of strontiumsubstituted hydroxyapatite coatings. J Mater Sci Mater Med. 2015;26(2):65.

17. Boyd AR, Duffy H, McCann R, Meenan BJ. Sputter deposition of calcium phosphate/titanium dioxide hybrid thin films. Mater Sci Eng C. 2008;28(2):228-36.

18. Boyd AR, Burke GA, Duffy H, Cairns ML, O'Hare P, Meenan BJ. Characterisation of calcium phosphate/titanium dioxide hybrid coatings. J Mater Sci Mater Med. 2008;19(2):485-98.

19. Zhao L, Liu L, Wu Z, Zhang Y, Chu PK. Effects of micropitted/nanotubular titania topographies on bone mesenchymal stem cell osteogenic differentiation. Biomaterials. 2012 Mar;33(9):2629-41.

20. McCafferty MM, Burke GA, Meenan BJ. Mesenchymal stem cell response to conformal sputter deposited calcium phosphate thin films on nanostructured titanium surfaces. J Biomed Mater Res A. 2014 Oct;102(10):3585-97.

21. Wopenka B, Pasteris JD. A mineralogical perspective on the apatite in bone. Mater Sci Eng C. 2005;25(2):131-43.

22. Gibson IR, Bonfield W. Novel synthesis and characterization of an AB-type carbonatesubstituted hydroxyapatite. J Biomed Mater Res. 2002;59(4):697-708.

23. Vallet-Regí M, González-Calbet JM. Calcium phosphates as substitution of bone tissues. Prog Solid State Chem. 2004;32(1-2):1-31.

24. Kim H, Camata RP, Chowdhury S, Vohra YK. In vitro dissolution and mechanical behavior of c-axis preferentially oriented hydroxyapatite thin films fabricated by pulsed laser deposition. Acta Biomater. 2010 Aug;6(8):3234-41.

25. Geesink RG, de Groot K, Klein CP. Bonding of bone to apatite-coated implants. J Bone Joint Surg Br. 1988 Jan;70(1):17-22.

26. Guo Y, Yao Y, Ning C, Guo Y, Chu L. Fabrication of mesoporous carbonated hydroxyapatite microspheres by hydrothermal method. Mater Lett. 2011 7/31;65(14):2205-8.

27. Magne D, Pilet P, Weiss P, Daculsi G. Fourier transform infrared microspectroscopic investigation of the maturation of nonstoichiometric apatites in mineralized tissues: a horse dentin study. Bone. 2001 Dec;29(6):547-52.

28. Wu J, Hayakawa S, Tsuru K, Osaka A. Low-Temperature Preparation of Anatase and Rutile Layers on Titanium Substrates and Their Ability To Induce in Vitro Apatite Deposition. J Am Ceram Soc. 2004;87(9):1635-42. 
29. Lovmand J, Justesen J, Foss M, Lauridsen RH, Lovmand M, Modin C, et al. The use of combinatorial topographical libraries for the screening of enhanced osteogenic expression and mineralization. Biomaterials. 2009 Apr;30(11):2015-22.

30. Kulterer B, Friedl G, Jandrositz A, Sanchez-Cabo F, Prokesch A, Paar C, et al. Gene expression profiling of human mesenchymal stem cells derived from bone marrow during expansion and osteoblast differentiation. BMC Genomics. 2007 Mar 12;8:70.

31. Aubin JE. Regulation of osteoblast formation and function. Rev Endocr Metab Disord. 2001 Jan;2(1):81-94.

32. Dorozhkin SV. Surface reactions of apatite dissolution. J Colloid Interface Sci. 1997;191(2):489-97.

33. Dorozhkin SV. A review on the dissolution models of calcium apatites. Prog Cryst Growth Charact Mater. 2002;44(1):45-61.

34. Shui C, Spelsberg TC, Riggs BL, Khosla S. Changes in Runx2/Cbfa1 expression and activity during osteoblastic differentiation of human bone marrow stromal cells. J Bone Miner Res. 2003 Feb;18(2):213-21.

35. Komori T. Regulation of bone development and extracellular matrix protein genes by RUNX2. Cell Tissue Res. 2010 Jan;339(1):189-95.

36. Oliveira NC, Moura CC, Zanetta-Barbosa D, Mendonca DB, Cooper L, Mendonca G, et al. Effects of titanium surface anodization with $\mathrm{CaP}$ incorporation on human osteoblastic response. Mater Sci Eng C Mater Biol Appl. 2013 May 1;33(4):1958-62.

37. Mendonca G, Mendonca DB, Simoes LG, Araujo AL, Leite ER, Duarte WR, et al. The effects of implant surface nanoscale features on osteoblast-specific gene expression. Biomaterials. 2009 Sep;30(25):4053-62.

38. Mendonca G, Mendonca DB, Aragao FJ, Cooper LF. The combination of micron and nanotopography by $\mathrm{H}(2) \mathrm{SO}(4) / \mathrm{H}(2) \mathrm{O}(2)$ treatment and its effects on osteoblast-specific gene expression of hMSCs. J Biomed Mater Res A. 2010 Jul;94(1):169-79.

39. Jikko A, Harris SE, Chen D, Mendrick DL, Damsky CH. Collagen integrin receptors regulate early osteoblast differentiation induced by BMP-2. J Bone Miner Res. 1999 Jul;14(7):1075-83.

40. Bodine PV, Komm BS. Wnt signaling and osteoblastogenesis. Rev Endocr Metab Disord. 2006 Jun;7(1-2):33-9.

41. Kim SY, Yoo JY, Ohe JY, Lee JW, Moon JH, Kwon YD, et al. Differential expression of osteomodulatory molecules in periodontal ligament stem cells in response to modified titanium surfaces. Biomed Res Int. 2014;2014:452175.

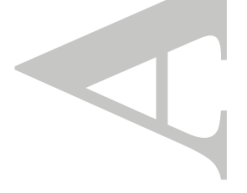




\section{List of Tables}

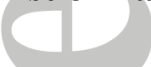

Table 1. Nomenclature for the surfaces prepared for this study.

Table 2. qPCR primer information

Table 3. XPS peak position data for the cpTi, TiTi and CaP-TiTi surfaces.

Table 4. XPS quantitative data for the cpTi, TiTi and CaP-TiTi surfaces.

Table 5. Surface feature size and surface roughness values from AFM analysis of cpTi, TiTi and CaP-TiTi.
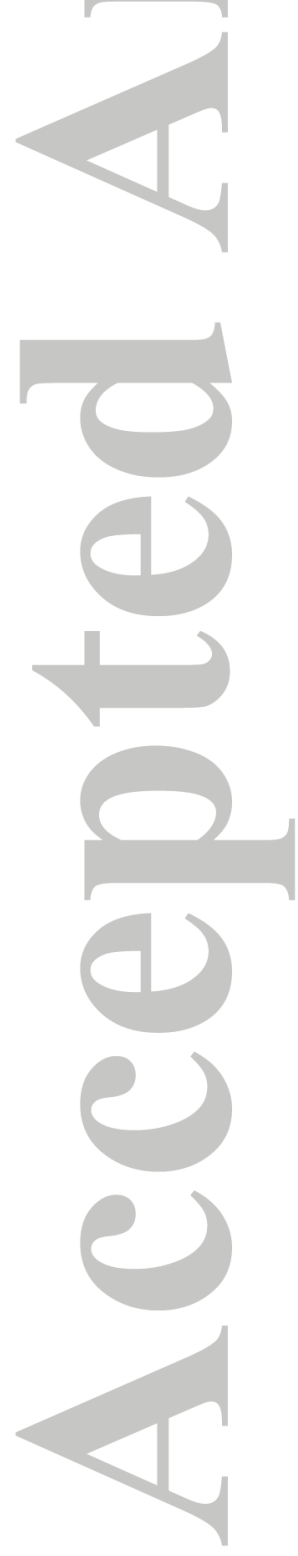

John Wiley \& Sons, Inc.

This article is protected by copyright. All rights reserved. 


\section{Figure Captions}

Figure 1. FTIR Spectrum for CaP-TiTi sample.

Figure 2. XRD diffractograms for (a) abraded chemically pure titanium surface (cpTi), (b) titanium layer sputtered onto a cpTi surface (TiTi) and (c and d) CaP coating on TiTi surface (CaP-TiTi).

Figure 3. XPS wide energy survey scans (WESS) for (a) abraded chemically pure titanium surface (cpTi), (b) titanium layer sputtered onto a cpTi surface (TiTi) and (c) CaP coating on TiTi surface (CaP-TiTi).

Figure 4. XPS high resolution spectra for abraded titanium surface cpTi where (a) C1s, (b) O1s and (c) Ti2p. Similar high resolution spectra for sputtered titanium surface (TiTi) are provided for (d) C1s, (e) O1s and (f) Ti2p.

Figure 5. XPS high resolution spectra for the CaP-TiTi, where (a) C1s, (b) O1s, (c) Ca2p and (d) $\mathrm{P} 2 \mathrm{p}$.

Figure 6. AFM images for (a) abraded titanium surface (cpTi), (b) titanium layer sputtered onto a cpTi surface (TiTi) and (c) CaP coating on TiTi surface (CaP-TiTi).

Figure 7. PDLSC bone-specific gene expression for ALPL, COL1A1, SPP1, and RUNX2. Levels provided as fold change relative to the day $7 \mathrm{cpTi}$ surface. *p $<0.05$ (ANOVA - post-test Tukey’s)

Figure 8. PDLSC Wnt pathway gene expression (A) CTNNB1 and (B) WNT5A at days 14 and 21. Levels provided as fold change relative to the day $14 \mathrm{cpTi}$ surface. ${ }^{*} \mathrm{p}<0.05$ (ANOVA - post-test Tukey's)

Figure 9. Alkaline Phosphatase (ALP) activity for cpTi, TiTi and CaP-TiTi surfaces at days 7, 14, and 21. Values were normalized to total protein content and expressed as mean \pm SE $\eta m o l$ PNPP/min/mg protein. * $<<0.05$ (Kruskal-Wallis - post-test Dunn’s) 
Table 1. Nomenclature for the surfaces prepared for this study.

\begin{tabular}{|l|c|c|}
\hline Sample Name & Nomenclature & Coating Thickness (nm) \\
\hline Chemically pure titanium & cpTi & - \\
\hline Titanium coated cpTi surfaces & TiTi & $\sim 100 \mathrm{~nm}$ \\
\hline Hydroxyapatite coated onto the TiTi surfaces & CaP-TiTi & $\sim 250 \mathrm{~nm}$ \\
\hline
\end{tabular}
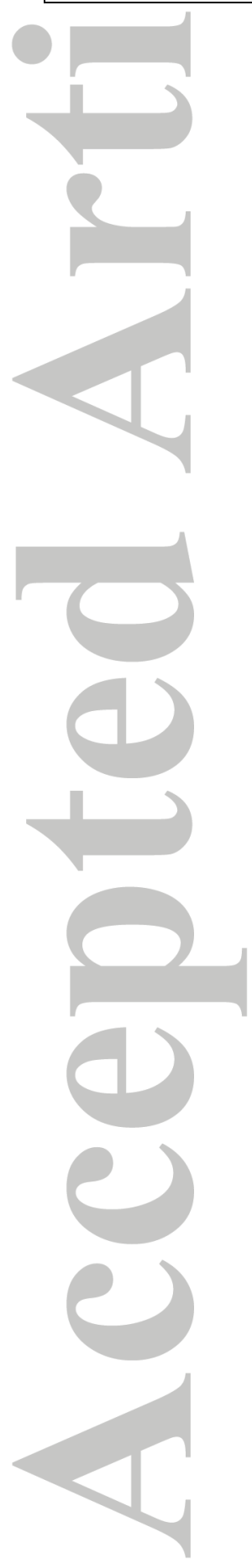

John Wiley \& Sons, Inc.

This article is protected by copyright. All rights reserved. 
Table 2. qPCR primer information

\begin{tabular}{|c|c|c|c|c|c|}
\hline Gene & Reference No. & $\begin{array}{l}\text { Chromosome } \\
\text { No. }\end{array}$ & $\begin{array}{l}\text { Probe } \\
\text { sits on } \\
\text { exon } \\
\text { boundary }\end{array}$ & $\begin{array}{l}\text { Base } \\
\text { position }\end{array}$ & $\begin{array}{l}\text { Amplicon } \\
\text { length }\end{array}$ \\
\hline COL1A1 & Hs00164004_ml & 17 & $1-2$ & 230 & 66 \\
\hline RUNX2 & Hs00231692_m1 & 6 & $\begin{array}{l}5-6 \\
5-6 \\
3-4 \\
\end{array}$ & $\begin{array}{l}900 \\
900 \\
648 \\
\end{array}$ & 116 \\
\hline & Hs01029144_m1 & 1 & $\begin{array}{l}7-8 \\
6-7 \\
5-6 \\
\end{array}$ & $\begin{array}{l}1056 \\
891 \\
775 \\
\end{array}$ & 79 \\
\hline SPP1 & Hs00959010_m1 & 4 & $\begin{array}{l}5-6 \\
6-7 \\
5-6 \\
4-5 \\
7-8 \\
4-5 \\
\end{array}$ & $\begin{array}{l}657 \\
699 \\
618 \\
576 \\
888 \\
1125 \\
\end{array}$ & 84 \\
\hline CTNNB1 & Hs00355045_m1 & 3 & $\begin{array}{l}10-11 \\
10-11 \\
10-11 \\
10-11 \\
10-11\end{array}$ & $\begin{array}{l}1948 \\
1962 \\
1860 \\
1922 \\
1962\end{array}$ & 86 \\
\hline WNT5A & Hs00998537_m1 & 3 & $\begin{array}{l}4-5 \\
4-5 \\
4-5 \\
7-8 \\
7-8 \\
4-5 \\
4-5 \\
4-5 \\
8-9 \\
7-8\end{array}$ & $\begin{array}{l}748 \\
1343 \\
703 \\
6332 \\
2956 \\
849 \\
1994 \\
895 \\
6059 \\
2961\end{array}$ & 61 \\
\hline $\mathrm{B} 2 \mathrm{M}$ & HS00984230_m1 & 15 & $3-4$ & 431 & 81 \\
\hline GUSB & HS00939627_m1 & 7 & $8-9$ & 1522 & 96 \\
\hline
\end{tabular}

John Wiley \& Sons, Inc.

This article is protected by copyright. All rights reserved. 
Table 3. XPS peak position data for the cpTi, TiTi and CaP-TiTi surfaces.

\begin{tabular}{|c|c|c|c|c|c|c|}
\hline \multirow{2}{*}{ Sample } & \multicolumn{6}{|c|}{ Peak Position (eV) } \\
\hline & C1s & O1s & $\mathrm{Ca} 2 \mathrm{p}_{3 / 2}$ & P2p & $\mathbf{T i 2} \mathbf{p}_{3 / 2}$ & N1s \\
\hline сpTi & 285.0 & 530.4 & 1 & I & 458.6 & 400.8 \\
\hline Ti on $\mathrm{Ti}$ & 285.0 & 530.2 & I & I & 459.0 & 401.2 \\
\hline HA on $\mathrm{Ti} 500^{\circ} \mathrm{C}$ & 285.0 & 531.6 & 347.6 & 133.6 & I & I \\
\hline
\end{tabular}
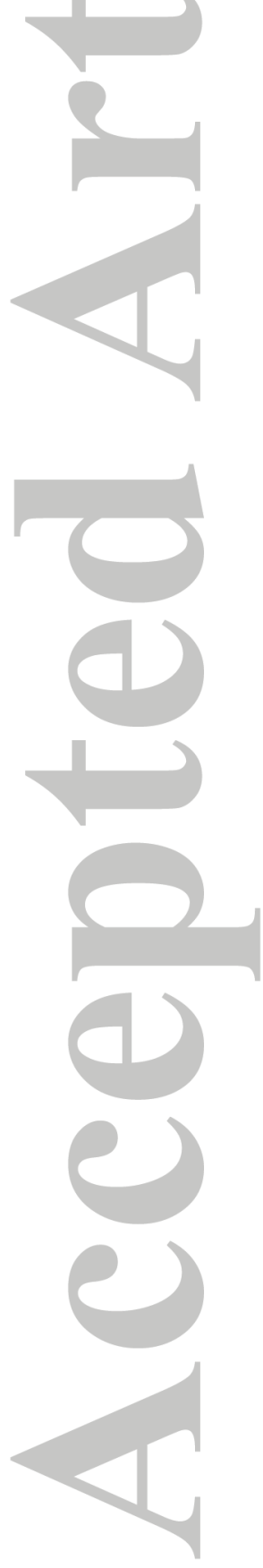

John Wiley \& Sons, Inc.

This article is protected by copyright. All rights reserved. 
Table 4. XPS quantitative data for the cpTi, TiTi and CaP-TiTi surfaces.

\begin{tabular}{|l|c|c|c|c|c|c|c|}
\hline \multirow{2}{*}{ Sample } & \multicolumn{6}{c|}{ Atomic Conc \% } & \multirow{2}{*}{ Ca/P Ratio } \\
\cline { 2 - 8 } & C1s & O1s & Ca2p & P2p & Ti2p & N1s & \\
\hline cpTi & 25.7 & 48.1 & $/$ & $/$ & 26.2 & $/$ & $/$ \\
\hline TiTi & 31.9 & 43.5 & $/$ & $/$ & 23.3 & 1.3 & $/$ \\
\hline CaP-TiTi & 18.1 & 55.8 & 15.6 & 10.4 & $/$ & $/$ & $1.74 \pm 0.14$ \\
\hline
\end{tabular}
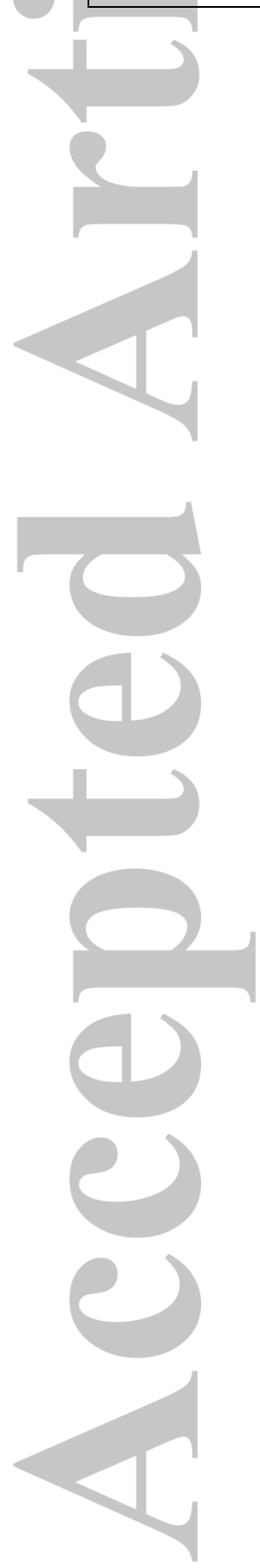

John Wiley \& Sons, Inc.

This article is protected by copyright. All rights reserved. 
Table 5. Surface feature size and surface roughness values from AFM analysis of cpTi, TiTi and CaP-TiTi.

\begin{tabular}{|c|c|c|c|}
\hline Sample Name & Surface Feature Size $(\mu \mathbf{m})$ & $\mathbf{R}_{\mathbf{a}}(\mu \mathbf{m})$ & $\mathbf{R}_{\mathbf{q}}(\boldsymbol{\mu m})$ \\
\hline cpTi & - & $40.6 \pm 9.0$ & $49.6 \pm 10.7$ \\
\hline TiTi & $0.39 \pm 0.05$ & $30.7 \pm 9.1$ & $39.1 \pm 11.8$ \\
\hline CaP-TiTi & $0.32 \pm 0.07$ & $25.4 \pm 5.2$ & $31.5 \pm 6.0$ \\
\hline
\end{tabular}

John Wiley \& Sons, Inc.

This article is protected by copyright. All rights reserved. 


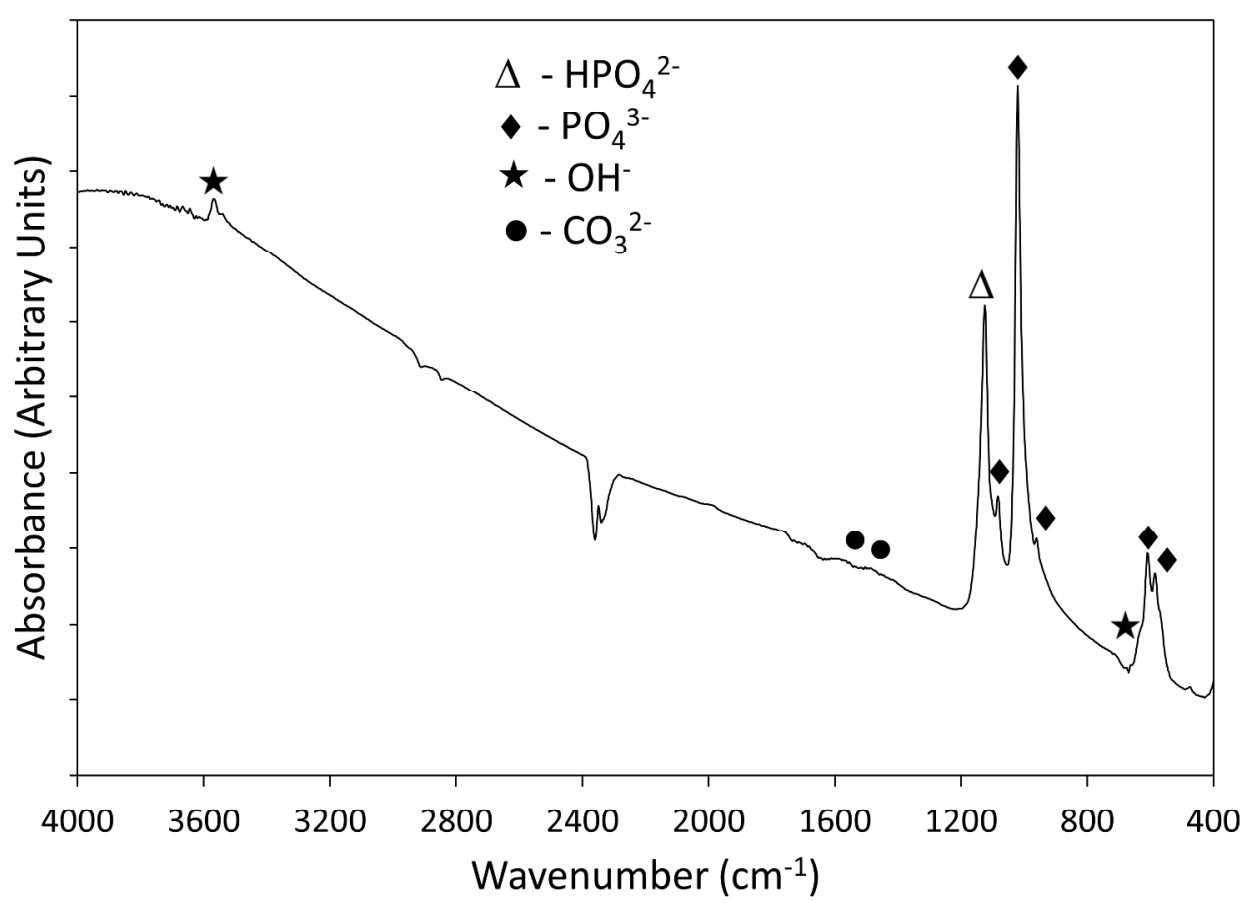

Figure 1. FTIR Spectrum for CaP-TiTi sample.

Figure 1

$254 \times 190 \mathrm{~mm}(300 \times 300$ DPI)

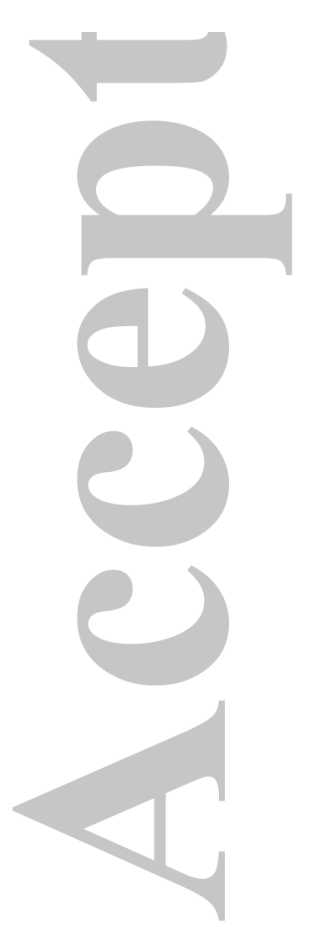

John Wiley \& Sons, Inc.

This article is protected by copyright. All rights reserved. 


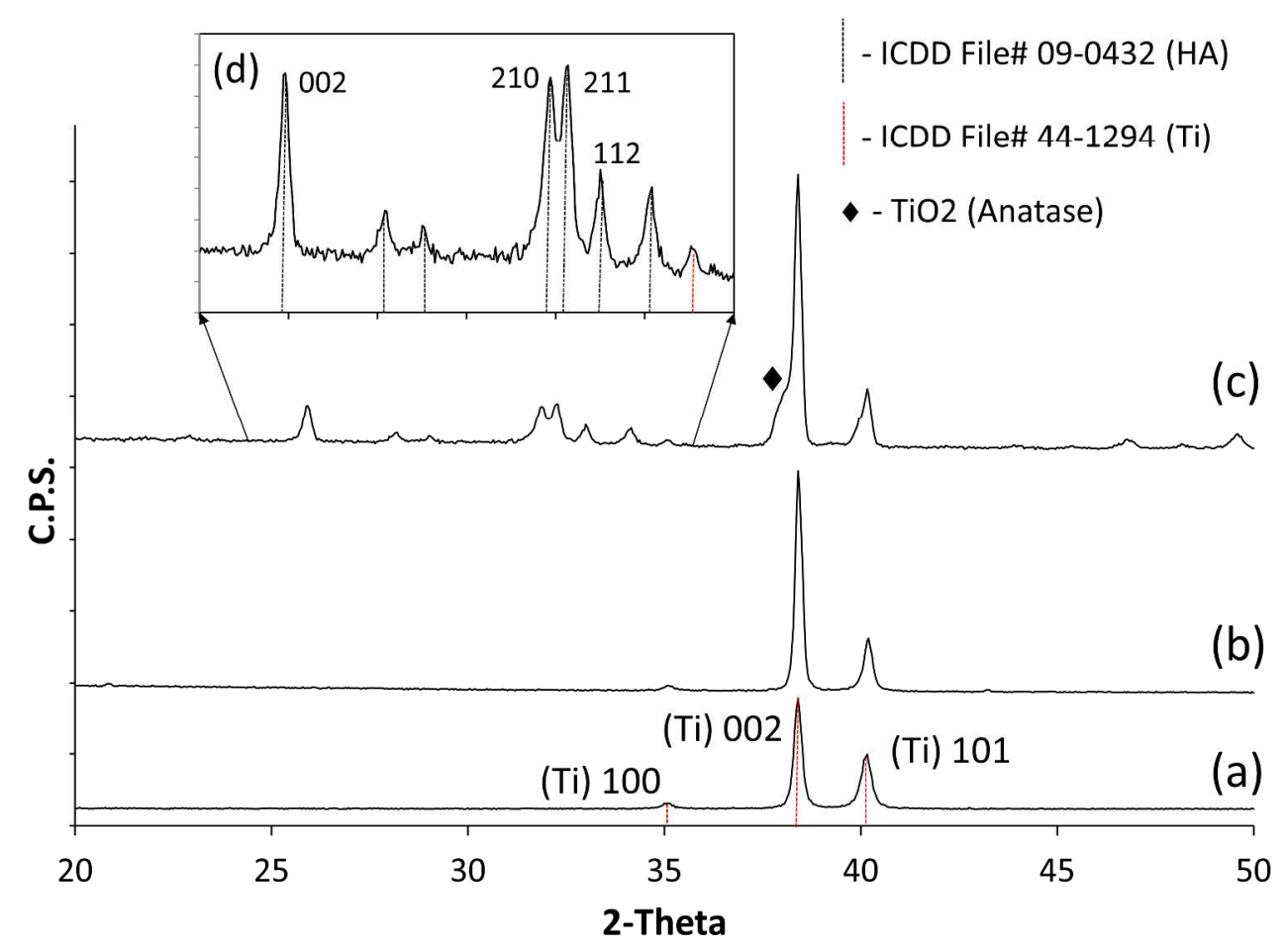

Figure 2. XRD diffractograms for (a) abraded chemically pure titanium surface (cpTi), (b) titanium layer sputtered onto a cpTi surface (TiTi) and (c and d) CaP coating on TiTi surface (CaP-TiTi).

Figure 2

$254 \times 190 \mathrm{~mm}(300 \times 300 \mathrm{DPI})$

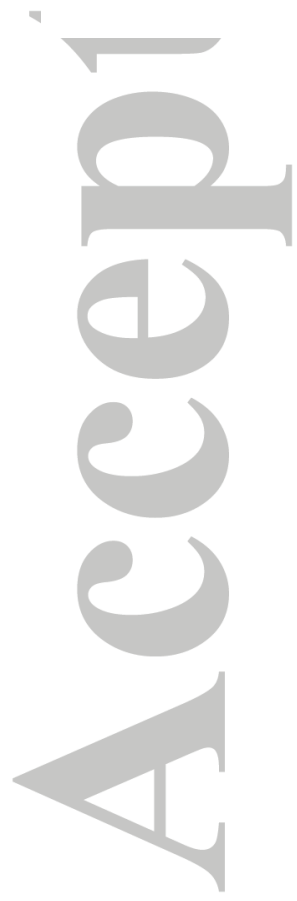

John Wiley \& Sons, Inc.

This article is protected by copyright. All rights reserved. 


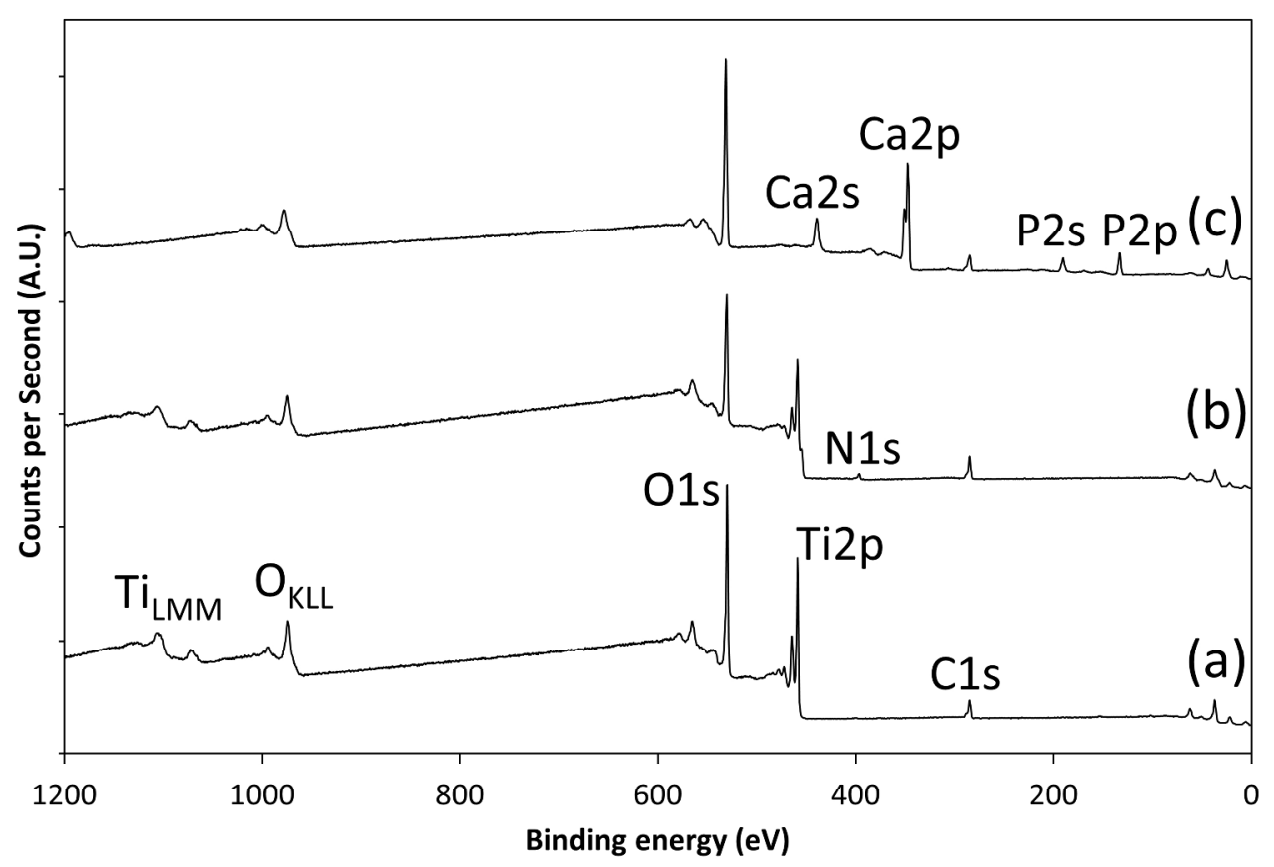

Figure 3. XPS wide energy survey scans (WESS) for (a) abraded chemically pure titanium surface (cpTi), (b) titanium layer sputtered onto a cpTi surface (TiTi) and (c) CaP coating on TiTi surface (CaP-TiTi). Figure 3

$254 \times 190 \mathrm{~mm}(300 \times 300$ DPI)

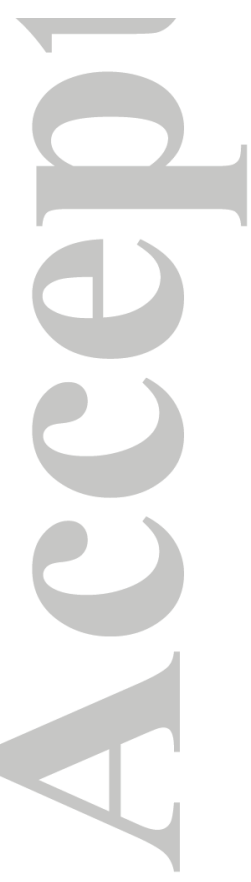

John Wiley \& Sons, Inc.

This article is protected by copyright. All rights reserved. 

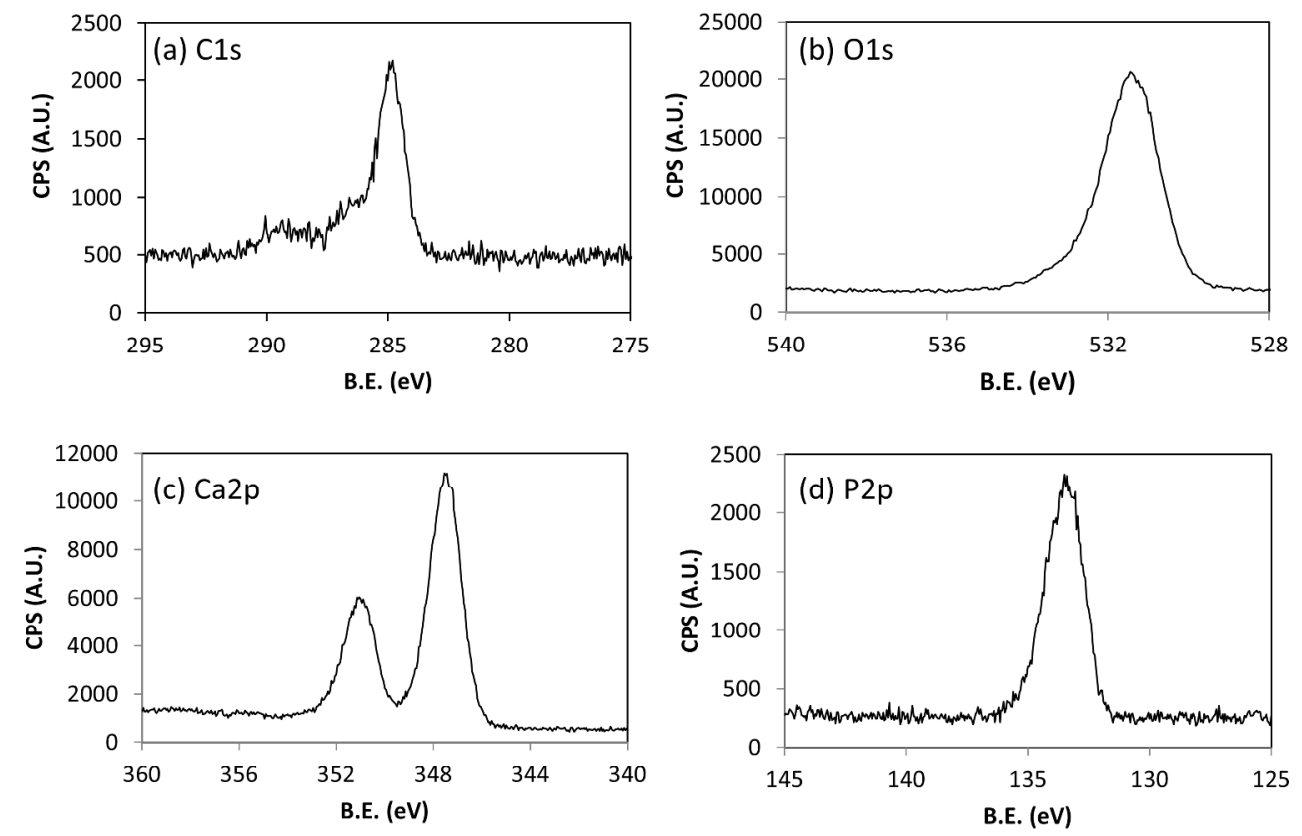

Figure 4. XPS high resolution spectra for abraded titanium surface cpTi where (a) C1s, (b) O1s and (c) Ti2p. Similar high resolution spectra for sputtered titanium surface (TiTi) are provided for (d) C1s, (e) O1s and (f) Ti2p.

Figure 4

$254 \times 190 \mathrm{~mm}(300 \times 300 \mathrm{DPI})$

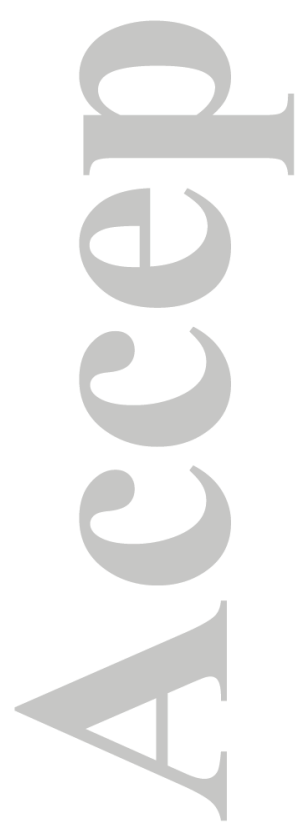

John Wiley \& Sons, Inc.

This article is protected by copyright. All rights reserved. 

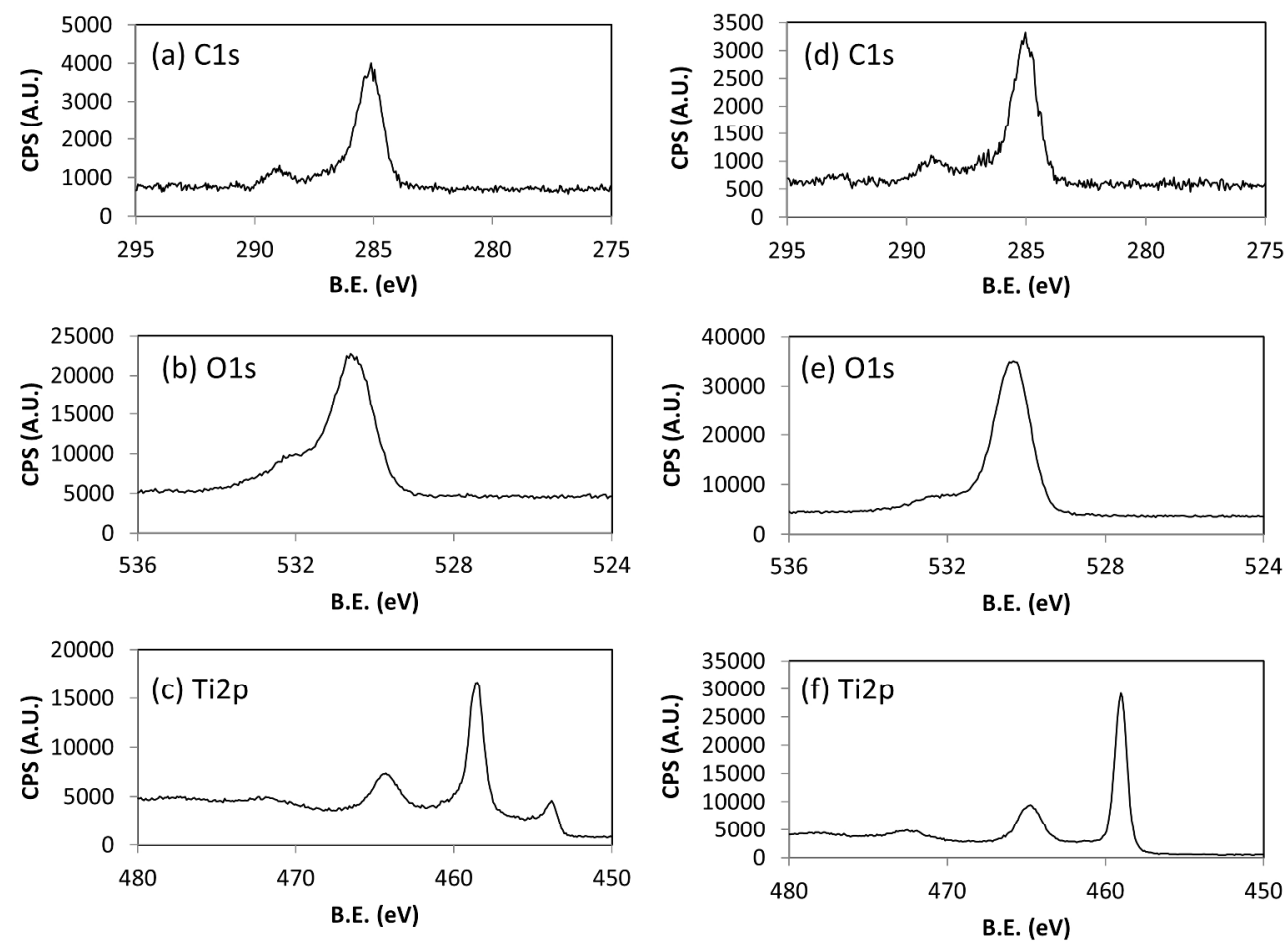

Figure 5. XPS high resolution spectra for the CaP-TiTi, where (a) C1s, (b) O1s, (c) Ca2p and (d) P2p. Figure 5

$254 \times 190 \mathrm{~mm}(300 \times 300$ DPI $)$

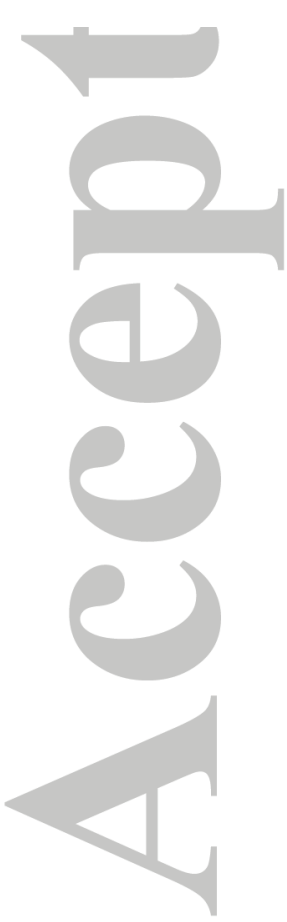

John Wiley \& Sons, Inc.

This article is protected by copyright. All rights reserved. 
(a)

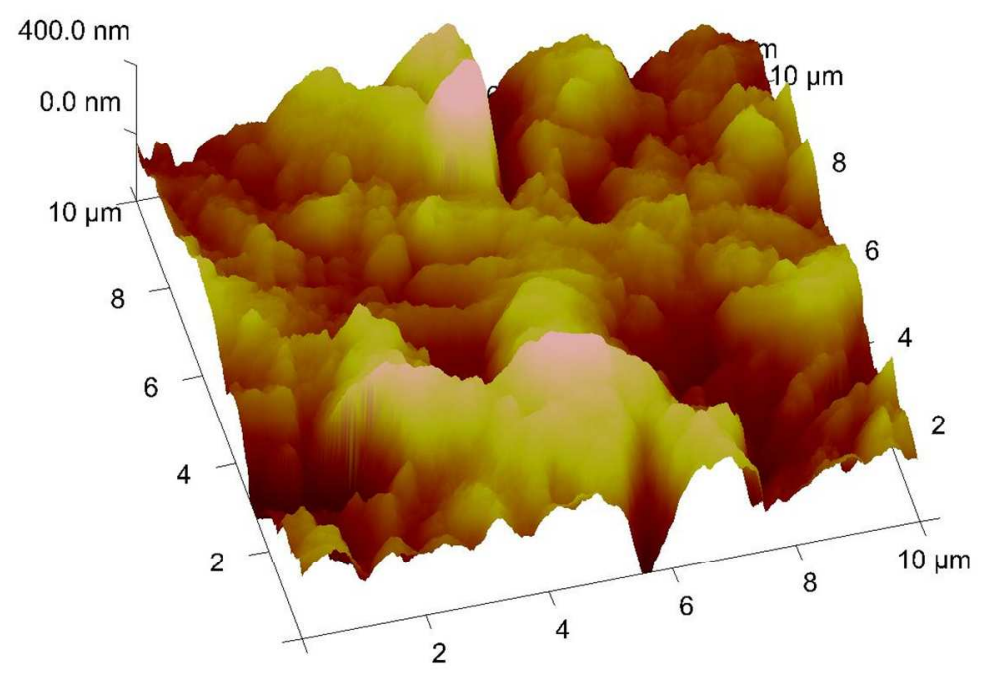

Figure 6. AFM images for (a) abraded titanium surface (cpTi), (b) titanium layer sputtered onto a cpTi surface (TiTi) and (c) CaP coating on TiTi surface (CaP-TiTi).

Figure $6 a$

$254 \times 190 \mathrm{~mm}(300 \times 300 \mathrm{DPI})$

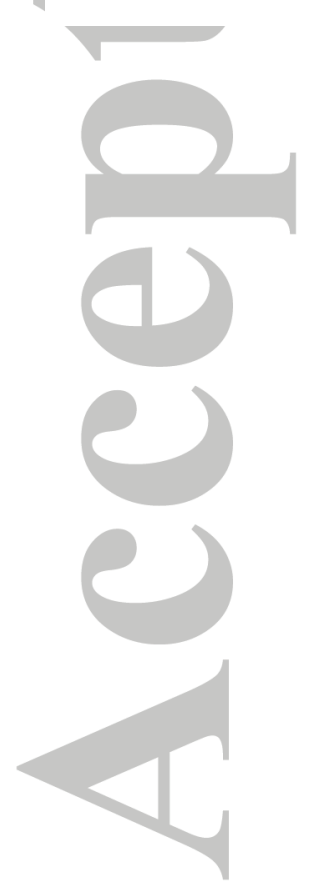

John Wiley \& Sons, Inc.

This article is protected by copyright. All rights reserved. 
(b)

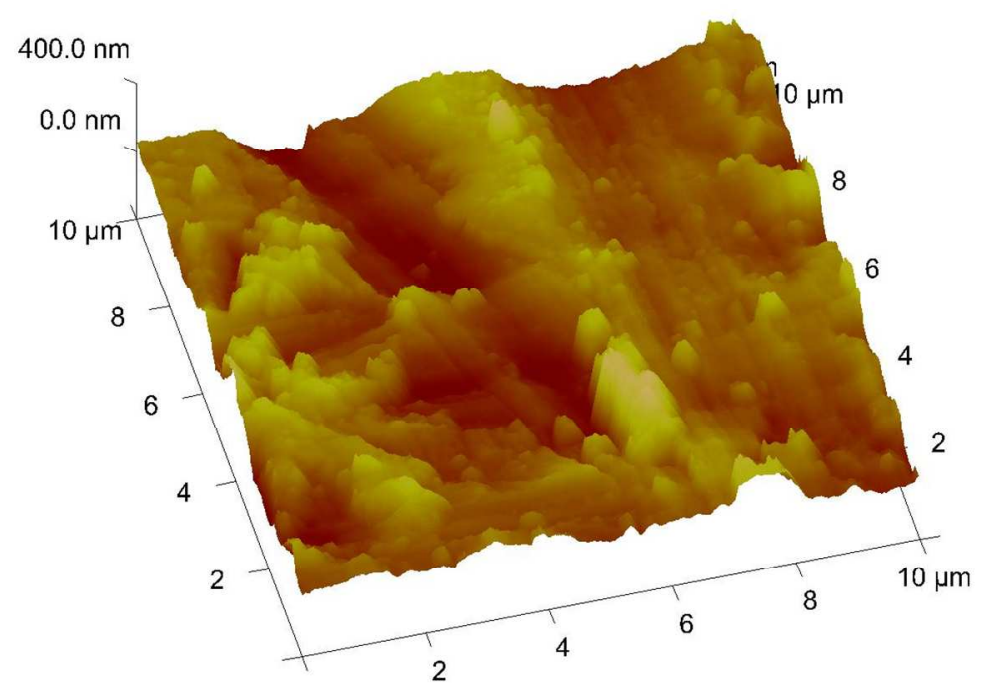

Figure 6. AFM images for (a) abraded titanium surface (cpTi), (b) titanium layer sputtered onto a cpTi surface (TiTi) and (c) CaP coating on TiTi surface (CaP-TiTi).

$$
\text { Figure } 6 \mathrm{~b}
$$

$254 \times 190 \mathrm{~mm}(300 \times 300$ DPI)

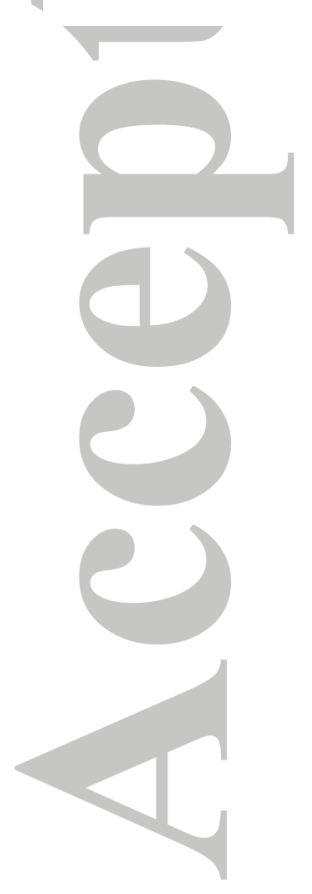

John Wiley \& Sons, Inc.

This article is protected by copyright. All rights reserved. 
(c)

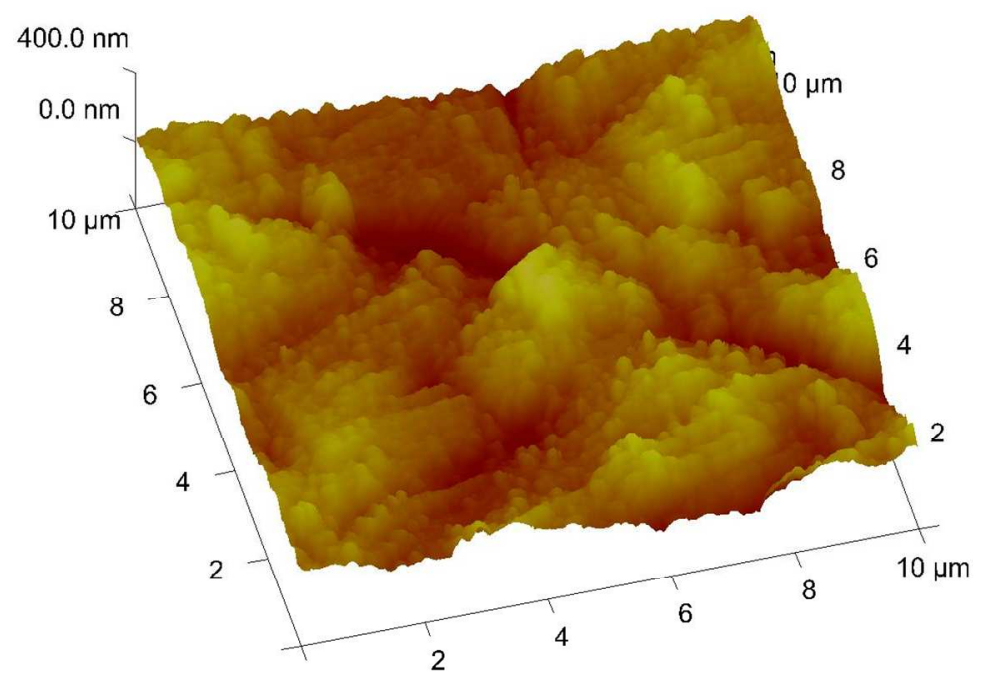

Figure 6. AFM images for (a) abraded titanium surface (cpTi), (b) titanium layer sputtered onto a cpTi surface (TiTi) and (c) CaP coating on TiTi surface (CaP-TiTi).

$$
\text { Figure } 6 \mathrm{c}
$$

$254 \times 190 \mathrm{~mm}(300 \times 300$ DPI)

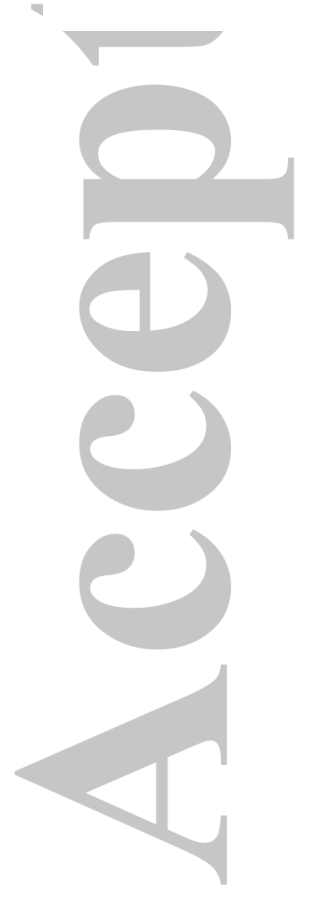

John Wiley \& Sons, Inc.

This article is protected by copyright. All rights reserved. 

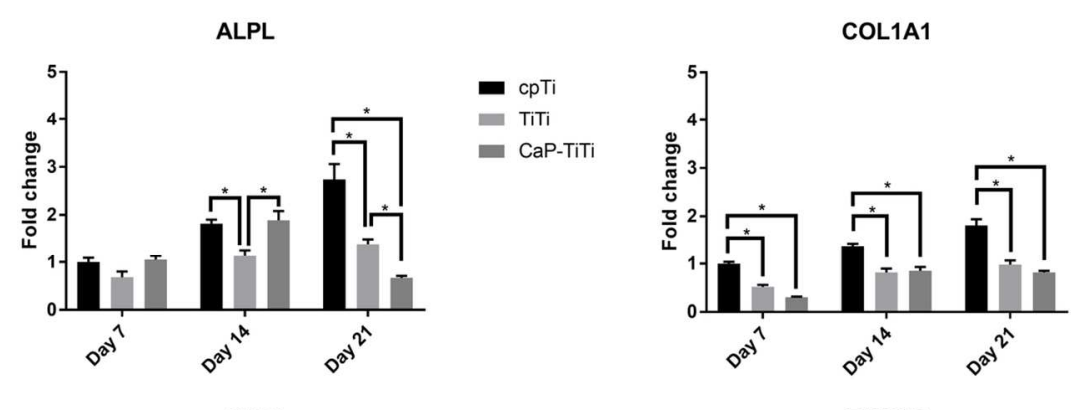

$$
\begin{aligned}
& \text { cpTi } \\
& \text { TiTi } \\
& \text { CaP-TiTi }
\end{aligned}
$$
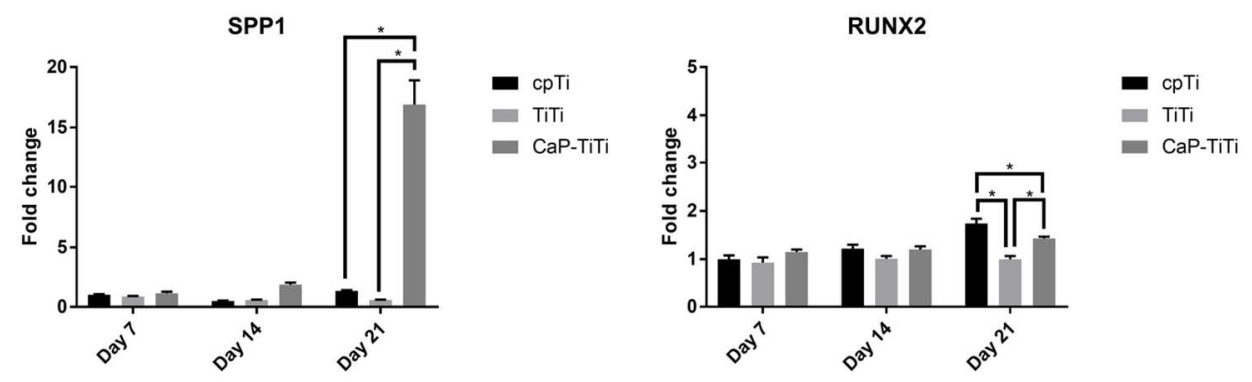

Figure 7. PDLSC bone-specific gene expression for ALPL, COL1A1, SPP1, and RUNX2. Levels provided as fold change relative to the day $7 \mathrm{cpTi}$ surface. ${ }^{*} \mathrm{p}<0.05$ (ANOVA - post-test Tukey's) Figure 7

$125 \times 80 \mathrm{~mm}(300 \times 300 \mathrm{DPI})$

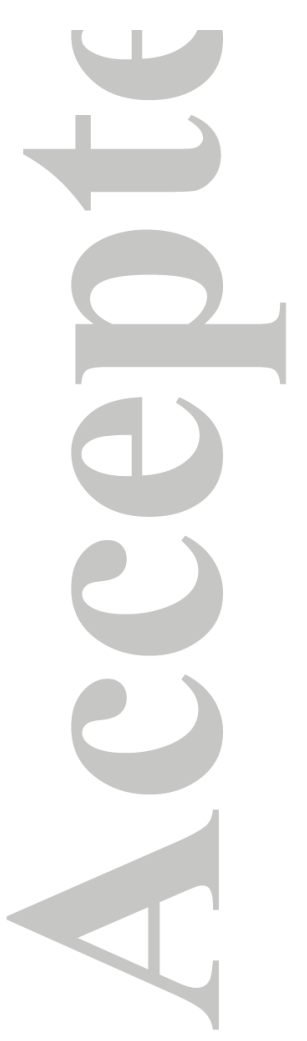

John Wiley \& Sons, Inc.

This article is protected by copyright. All rights reserved. 
CTNNB1

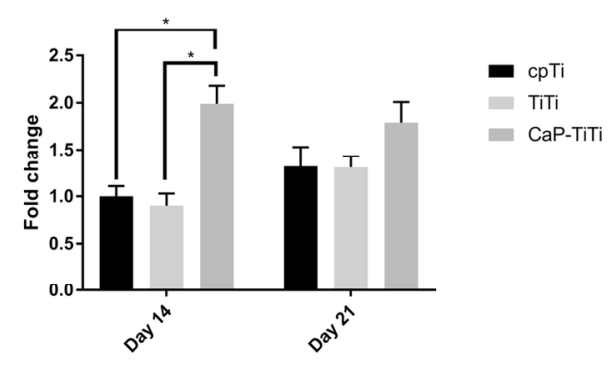

WNT5A

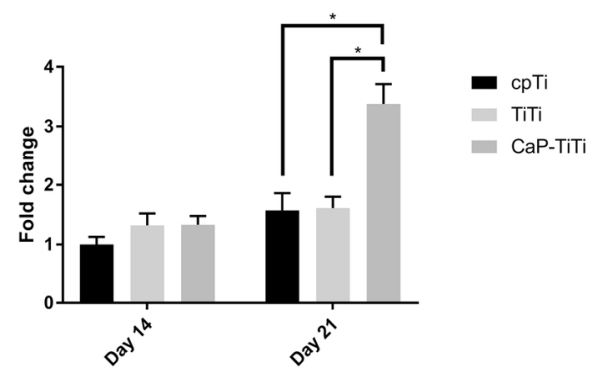

Figure 8: PDLSC Wnt pathway gene expression (A) CTNNB1 and (B) WNT5A at days 14 and 21. Levels provided as fold change relative to the day $14 \mathrm{cpTi}$ surface. ${ }^{*} \mathrm{p}<0.05$ (ANOVA - post-test Tukey's)

Figure 8

$75 \times 29 m m(600 \times 600$ DPI $)$

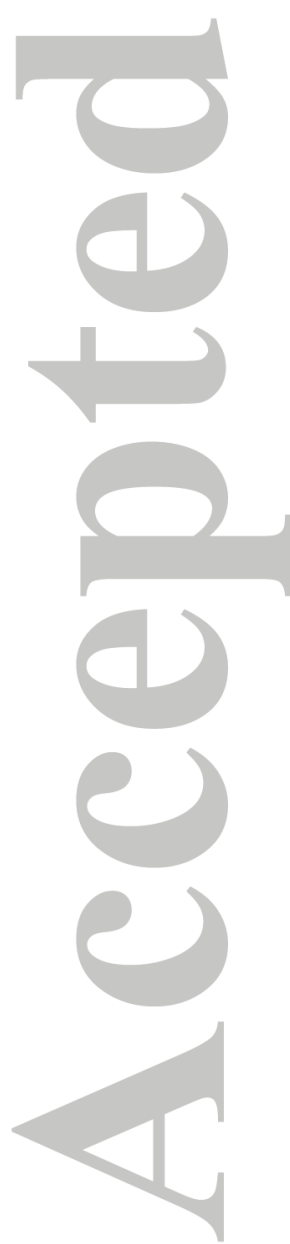

John Wiley \& Sons, Inc.

This article is protected by copyright. All rights reserved. 


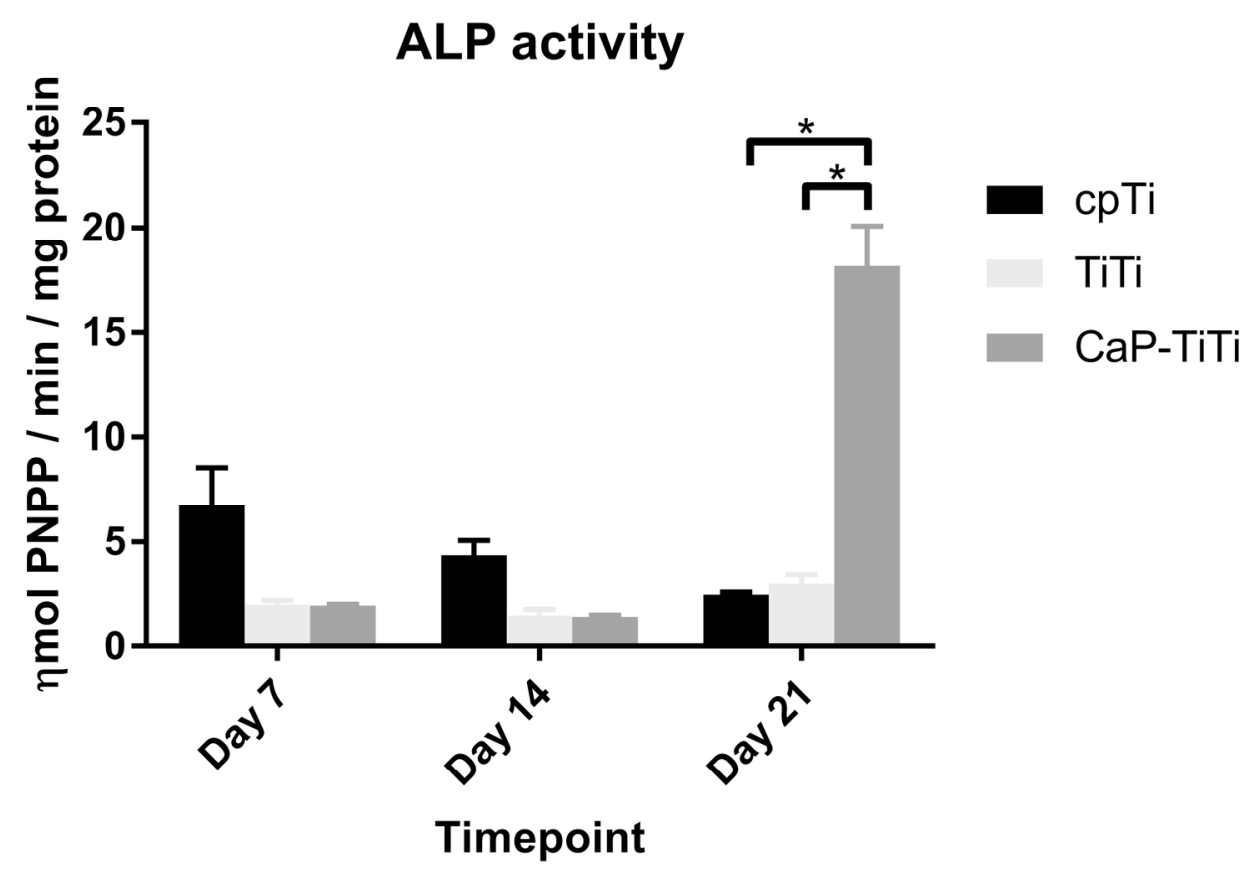

Figure 9: Alkaline Phosphatase (ALP) activity for cpTi, TiTi and CaP-TiTi surfaces at days 7, 14, and 21. Values were normalized to total protein content and expressed as mean \pm SE $\eta \mathrm{mol} \mathrm{PNPP} / \mathrm{min} / \mathrm{mg} \mathrm{protein}$. *p $<0.05$ (Kruskal-Wallis - post-test Dunn's)

Figure 9

$89 \times 63 \mathrm{~mm}(600 \times 600 \mathrm{DPI})$

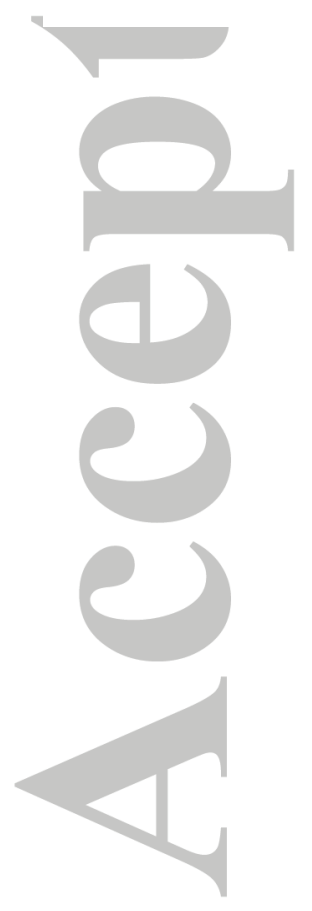

John Wiley \& Sons, Inc. 
A

B
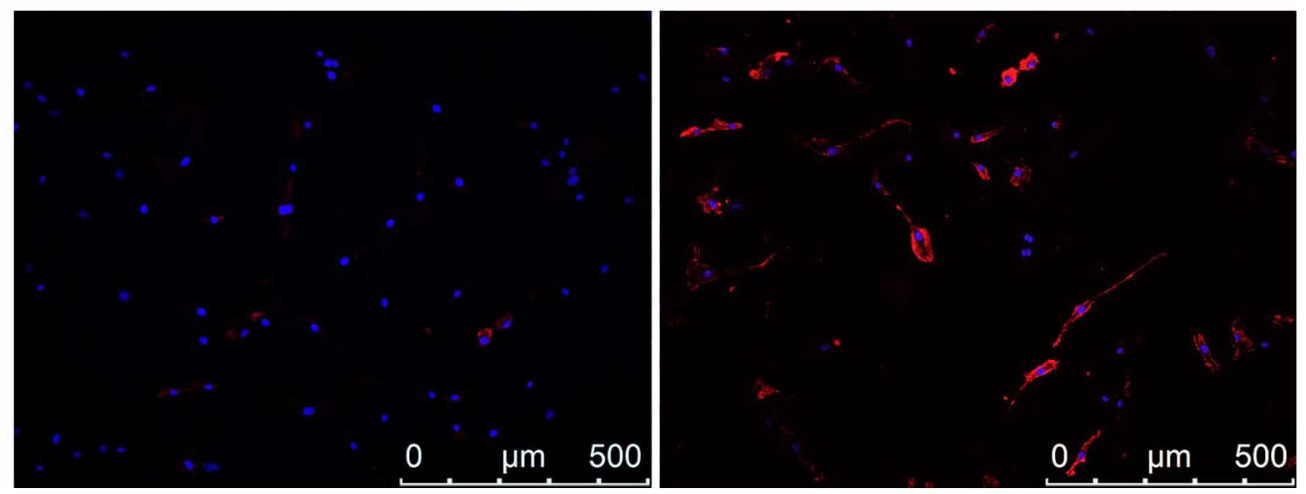

Figure S1 Caption: Captured immunofluorescent images of mixed population periodontal ligament cells (A), and Stro-1 sorted periodontal ligament stem cells (B). Red: Stro-1. Blue: Nuclei (DAPI)

Figure $\mathrm{S} 1$

$300 \times 128 \mathrm{~mm}(300 \times 300 \mathrm{DPI})$

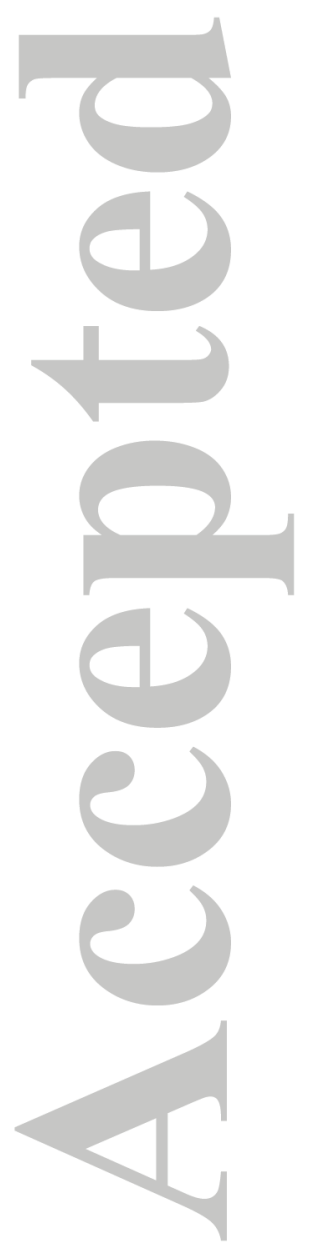

John Wiley \& Sons, Inc.

This article is protected by copyright. All rights reserved. 